\title{
A Novel Epilepsy Mutation in the Sodium Channel SCN1A Identifies a Cytoplasmic Domain for $\beta$ Subunit Interaction
}

\author{
J. Spampanato, ${ }^{1}$ J. A. Kearney, ${ }^{3}$ G. de Haan, ${ }^{3}$ D. P. McEwen, ${ }^{4}$ A. Escayg, ${ }^{3}$ I. Aradi, ${ }^{2}$ B. T. MacDonald, ${ }^{3}$ S. I. Levin, ${ }^{3}$ \\ I. Soltesz, ${ }^{2}$ P. Benna, ${ }^{5}$ E. Montalenti, ${ }^{5}$ L. L. Isom, ${ }^{4}$ A. L. Goldin, ${ }^{1,2}$ and M. H. Meisler ${ }^{3}$ \\ Departments of ${ }^{1}$ Microbiology and Molecular Genetics and ${ }^{2}$ Anatomy and Neurobiology, University of California, Irvine, Irvine, California 92697-4025, \\ Departments of ${ }^{3}$ Human Genetics and ${ }^{4}$ Pharmacology, University of Michigan, Ann Arbor, Michigan 48109-0618, and ${ }^{5}$ Department of Neurosciences, \\ University of Torino, 10126 Torino, Italy
}

A mutation in the sodium channel SCN1A was identified in a small Italian family with dominantly inherited generalized epilepsy with febrile seizures plus (GEFS +). The mutation, D1866Y, alters an evolutionarily conserved aspartate residue in the C-terminal cytoplasmic domain of the sodium channel $\alpha$ subunit. The mutation decreased modulation of the $\alpha$ subunit by $\beta 1$, which normally causes a negative shift in the voltage dependence of inactivation in oocytes. There was less of a shift with the mutant channel, resulting in a $10 \mathrm{mV}$ difference between the wild-type and mutant channels in the presence of $\beta 1$. This shift increased the magnitude of the window current, which resulted in more persistent current during a voltage ramp. Computational analysis suggests that neurons expressing the mutant channels will fire an action potential with a shorter onset delay in response to a threshold current injection, and that they will fire multiple action potentials with a shorter interspike interval at a higher input stimulus. These results suggest a causal relationship between a positive shift in the voltage dependence of sodium channel inactivation and spontaneous seizure activity. Direct interaction between the cytoplasmic C-terminal domain of the wild-type $\alpha$ subunit with the $\beta 1$ or $\beta 3$ subunit was first demonstrated by yeast two-hybrid analysis. The SCN1A peptide K1846-R1886 is sufficient for $\beta$ subunit interaction. Coimmunoprecipitation from transfected mammalian cells confirmed the interaction between the $\mathrm{C}$-terminal domains of the $\alpha$ and $\beta 1$ subunits. The D1866Y mutation weakens this interaction, demonstrating a novel molecular mechanism leading to seizure susceptibility.

Key words: channel; epilepsy; kinetic (kinetics); mutant; sodium (Na); genetics

\section{Introduction}

Generalized epilepsy with febrile seizures plus (GEFS+) [MIM 604233 (Mendelian Inheritance in Man)] is an inherited epilepsy disorder characterized by febrile seizures persisting beyond the age of 6 years and progression to adult epilepsy (Scheffer and Berkovic, 1997; Singh et al., 1999). Mutations in four genes have been associated with GEFS + , the sodium channel $\alpha$ subunits SCN1A and SCN2A, the sodium channel $\beta 1$ subunit SCN1B, and the $\mathrm{GABA}_{\mathrm{A}}$ receptor $\gamma 2$ subunit GABRG2 (for review, see Meisler et al., 2001).

Since the description of the first SCN1A mutations in families with GEFS + in 2000, 10 additional mutations have been described, accounting for the disease in $50 \%$ of families studied (Escayg et al., 2000, 2001; Abou-Khalil et al., 2001; Sugawara et

Received May 26, 2004; revised Sept. 17, 2004; accepted Sept. 17, 2004.

This work was supported by National Institutes of Health (NIH) Grants NS34509 (M.H.M.), NS26729 and NS48336 (A.L.G.), MH59980 (L.L.I.), and NS38580 (I.S.) and by McKnight Award 34653 (A.L.G.). D.P.M. was supported by National Research Service Award NS43067 and by the University of Michigan Pharmacological Science Training Program (NIH Grant GM07767). S.I.L. acknowledges support from the Michigan Program in Biomedical Research Training for Veterinary Scientists (NIH Grant T32 RR07008). We thank Maja Adamska for assistance in the preparation of this manuscript.

Correspondence should be addressed to Dr. Miriam H. Meisler, Department of Human Genetics, University of Michigan, 4808 Medical Science II, 1241 East Catherine Street, Ann Arbor, MI 48109-0618. E-mail: meislerm@umich.edu.

DOI:10.1523/JNEUROSCI.2034-04.2004

Copyright $\odot 2004$ Society for Neuroscience $\quad 0270-6474 / 04 / 2410022-13 \$ 15.00 / 0$ al., 2001; Wallace et al., 2001; Annesi et al., 2003; Fujiwara et al., 2003; Lossin et al., 2003). Most of these are located within or adjacent to transmembrane segments or in the pore region of the channel. The biophysical characteristics of eight mutations have been examined, revealing an array of phenotypic variations in channel function (Spampanato et al., 2001, 2003; Lossin et al., 2002, 2003; Cossette et al., 2003). Functional characterization of additional disease alleles of SCN1A can further our understanding of the structure-function relationships of the channel protein.

SCN1A is one of nine paralogous genes in the mammalian genome encoding the large $\alpha$ subunits of the voltage-gated sodium channels (Plummer and Meisler, 1999; Goldin, 2001). These highly conserved transmembrane proteins contain four internally homologous domains, each with six transmembrane segments (Catterall, 2000). Voltage-dependent gating results from conformational changes initiated by transmembrane segments with multiple positive charges. The $\mathrm{N}$-terminal and C-terminal domains of the channel protein are localized in the cytoplasm, and the C-terminal domain is thought to contribute to channel inactivation (Mantegazza et al., 2001). Localization, cell surface expression and inactivation of the sodium channel $\alpha$ subunits are modified by interaction with a family of small $\beta$ subunits that are single-transmembrane proteins with extracellular immunoglobulin domains and short intracellular C-terminal domains 
(Isom et al., 1994; Yu et al., 2003). The $\alpha$ subunit encoded by SCN1A is designated $\mathrm{Na}_{\mathrm{v}} 1.1$ (Goldin et al., 2000).

We report here that the D1866Y mutation of SCN1A causes a positive shift in the voltage dependence of sodium channel fast inactivation, an increase in the magnitude of the persistent current and a delay in the kinetics of inactivation. Computational analysis of action potential generation suggests that these effects might alter the spike timing in a way that is consistent with neuronal hyperexcitability. The molecular basis for the biophysical alterations is impaired interaction between the cytoplasmic $\mathrm{C}$ termini of the $\alpha$ and $\beta 1$ subunits. The data define a novel interaction domain of the $\alpha$ subunit that is required for complete modulation of $\alpha$ subunits by $\beta 1$.

\section{Materials and Methods}

Mutation detection. The exons of SCN1A were amplified individually from genomic DNA in 28 PCRs and analyzed by conformation-sensitive gel electrophoresis as described previously (Escayg et al., 2000). PCR products with mobility variants were gel purified with the Qiaquick gel extraction kit (Qiagen, Valencia, CA) and manually sequenced using the Thermosequenase sequencing kit (United States Biochemicals, Cleveland, OH). Control samples were described previously (Escayg et al., 2001).

Expression and electrophysiology. The D1866Y mutation was constructed from two overlapping PCR products. Product 1 (1062 bp) was generated with the primer pair F1 (GCCACAAAAGCCTATCCCTCGACCTGG) and D1866YR (GTAAAAGCAAATAAGATGTCCAGGCAGTGGATGCGGTC). Product 2 (371 bp) was generated with the primer pair D1866YF (GACCGCATCCACTGCCTGGACATCTTATTTGCTTTTAC) and R1 (GGACAAGCTGCAGTGGACATCGTCAGG). Each PCR product $(0.5 \mu \mathrm{l})$ was combined and reamplified with the outside primers $\mathrm{F} 1$ and $\mathrm{R} 1$ to generate a $1395 \mathrm{bp}$ product that contains the D1866Y mutation. BssH1/BstEII digestion of this product generated a $1104 \mathrm{bp}$ fragment that was ligated with the BssH1/BstEII-digested wildtype channel cDNA. The mutant plasmid was grown in HB101 cells on LB-tetracycline plates. Resequencing of the complete coding sequence confirmed the presence of the D1866Y mutation and the absence of any other mutations.

mRNA was transcribed in vitro from NotI-linearized DNA templates and injected into stage $\mathrm{V}$ oocytes that had been removed from adult female Xenopus laevis frogs (Goldin, 1991). Oocytes were incubated in ND-96 media, which consisted of $96 \mathrm{~mm} \mathrm{NaCl}, 2 \mathrm{~mm} \mathrm{KCl}, 1.8 \mathrm{~mm} \mathrm{CaCl}_{2}$, $1 \mathrm{~mm} \mathrm{MgCl}_{2}$, and $5 \mathrm{~mm}$ HEPES, pH 7.5, supplemented with $0.1 \mathrm{mg} / \mathrm{ml}$ gentamicin, $0.55 \mathrm{mg} / \mathrm{ml}$ pyruvate, and $0.5 \mathrm{~mm}$ theophylline. RNA encoding the $\mathrm{Na}_{\mathrm{v}} 1.1$ and D1866Y channels were injected at $\sim 60 \mathrm{pg} /$ oocyte in the absence of the $\beta 1$ subunit and $\sim 30 \mathrm{pg} /$ oocyte in the presence of the $\beta 1$. When the channels were coexpressed with the $\beta 1$ subunit, at least a 10:1 molar ratio of $\beta 1$ to $\alpha$ mRNA was injected. Oocytes were incubated at $20^{\circ} \mathrm{C}$ for $>10 \mathrm{hr}$ in ND-96 before voltage clamping.

Sodium currents were recorded using the cut-open oocyte CA-1 High Performance Oocyte Voltage Clamp (Dagan, Minneapolis, MN) at $20^{\circ} \mathrm{C}$ (HCC-100A Temperature Controller; Dagan), with a DigiData 1321A interface (Axon Instruments, Foster City, CA) and pClamp 8.0 software (Axon Instruments) as described previously (Kontis et al., 1997). The external solution consisted of $120 \mathrm{~mm}$ sodium methanesulfonate, $10 \mathrm{~mm}$ HEPES, and $1.8 \mathrm{~mm}$ calcium methanesulfonate, $\mathrm{pH}$ 7.5. The internal solution consisted of $88 \mathrm{~mm} \mathrm{~K}_{2} \mathrm{SO}_{4}, 10 \mathrm{~mm}$ EGTA, 10 mM HEPES, and 10 $\mathrm{mM} \mathrm{Na}_{2} \mathrm{SO}_{4}$, pH 7.5. P/4 subtraction was used to eliminate capacitive transients and leak currents whenever possible. The fast-gated properties of recovery from inactivation and use dependence were recorded using the cut-open oocyte voltage clamp but analyzed using a baseline subtraction method because these two properties might be altered by the time requirements of $\mathrm{P} / 4$ subtraction.

The voltage dependence of activation was analyzed using a step protocol in which oocytes were depolarized from a holding potential of $-100 \mathrm{mV}$ to a range of potentials from -95 to $+50 \mathrm{mV}$ in $5 \mathrm{mV}$ increments. Peak currents were normalized to the maximum peak current and plotted against voltage. To calculate a reversal potential, the resulting $I-V$ curve of each data set was individually fit with the following equation:

$$
I=\left[1+\exp \left(-0.03937 \times z \times\left(V-V_{1 / 2}\right)\right)\right]^{-1} \times g \times\left(V-V_{1 / 2}\right),
$$

where $I$ is the current amplitude, $z$ is the apparent gating charge, $V$ is the potential of the given pulse, $V_{1 / 2}$ is the half-maximal voltage, $g$ is a factor related to the number of open channels during the given pulse, and $V_{\mathrm{r}}$ is the reversal potential. Conductance was then calculated directly using the equation $G=I /\left(V-V_{\mathrm{r}}\right)$, where $G$ is conductance and $I, V$, and $V_{\mathrm{r}}$ are as described above. The conductance values were fit with the two-state Boltzmann equation:

$$
G=1 /\left[1+\exp \left(-0.03937 \times z \times\left(V-V_{1 / 2}\right)\right)\right],
$$

where $z$ is the apparent gating charge, $V$ is the potential of the given pulse, and $V_{1 / 2}$ is the potential for half-maximal activation.

The voltage dependence of steady-state inactivation was determined using a two-step protocol in which a conditioning pulse was applied from a holding potential of $-100 \mathrm{mV}$ to a range of potentials from -100 to $+15 \mathrm{mV}$ in $5 \mathrm{mV}$ increments for $100 \mathrm{msec}$, immediately followed by a test pulse to $-5 \mathrm{mV}$. The peak current amplitudes during the subsequent test pulses were normalized to the peak current amplitude during the first test pulse, plotted against the potential of the conditioning pulse, and fit with the two-state Boltzmann equation:

$$
I=1 /\left[1+\exp \left(\left(V-V_{1 / 2}\right) / a\right)\right]
$$

where $I$ is equal to the test-pulse current amplitude, $V$ is the potential of the conditioning pulse, $V_{1 / 2}$ is the voltage for half-maximal inactivation, and $a$ is the slope factor.

The kinetics of fast inactivation were analyzed using the same protocol used to study the voltage dependence of activation. Inactivation time constants were determined using the Chebyshev method to fit each trace with either the following single-exponential equation:

$$
I=A_{\text {Slow }} \times \exp \left[-(t-K) / \tau_{\text {Slow }}\right]+C,
$$

or the double-exponential equation:

$I=A_{\text {Fast }} \times \exp \left[-(t-K) / \tau_{\text {Fast }}\right]+A_{\text {Slow }} \times \exp \left[-(t-K) / \tau_{\text {Slow }}\right]+C$,

where $I$ is the current, $A_{\text {Fast }}$ and $A_{\text {Slow }}$ are the relative proportions of current inactivating with the time constants $\tau_{\text {Fast }}$ and $\tau_{\text {Slow }}, K$ is the time shift, and $C$ is the steady-state non-inactivating current. The time shift was selected manually as the point at which the macroscopic current began to inactivate exponentially.

Recovery from inactivation was analyzed using three separate, twopulse protocols. Each protocol began with a conditioning depolarization from a holding potential of -100 to $-5 \mathrm{mV}$ for $50 \mathrm{msec}$, which inactivated $>95 \%$ of the channels. This was followed by a decreasing recovery time interval at $-100 \mathrm{mV}$ and a test depolarization to $-5 \mathrm{mV}$. The three protocols differed only in the maximum length of recovery time and the time interval by which that recovery period decreased: 25 msec maximum and $1 \mathrm{msec}$ decrements in the short protocol, $200 \mathrm{msec}$ maximum and $5 \mathrm{msec}$ decrements in the intermediate protocol, and $3000 \mathrm{msec}$ maximum and $100 \mathrm{msec}$ decrements in the long protocol. Fractional recovery was calculated by dividing the maximum current amplitude during the test pulse by the maximum current amplitude of the corresponding conditioning pulse. The recovery data were fit with either the following double-exponential equation:

$$
I=1-\left[A_{1} \times \exp \left(-t / \tau_{1}\right)+A_{2} \times \exp \left(-t / \tau_{2}\right)\right],
$$

or the triple-exponential equation:

$I=1-\left[A_{1} \times \exp \left(-t / \tau_{1}\right)+A_{2} \times \exp \left(-t / \tau_{2}\right)+A_{3}+\exp \left(\left(-\mathrm{t} / \tau_{3}\right)\right]\right.$,

where $A_{1}, A_{2}$, and $A_{3}$ are the relative percentages of current that recovered with the time constants $\tau_{1}, \tau_{2}$, and $\tau_{3}$, and $t$ is the recovery time.

Use dependence was analyzed at $39 \mathrm{~Hz}$ using $17.5 \mathrm{msec}$ depolarizations to $-10 \mathrm{mV}$ from a holding potential of $-100 \mathrm{mV}$. The protocol was 
continued for $2.56 \mathrm{sec}$, which was long enough for the current to have reached equilibrium. Peak current amplitudes were normalized to the peak current amplitude during the first depolarization and plotted against the time corresponding to the beginning of each depolarization.

Ramp currents were recorded at room temperature on the twoelectrode voltage clamp in ND-96 without supplements using a slow voltage change of $15 \mathrm{mV}$ per $200 \mathrm{msec}$ from a holding potential of - 100 to $+50 \mathrm{mV}$. Tetrodotoxin (TTX) subtraction was used to eliminate all non-TTX-sensitive currents by subtracting those currents recorded in the presence of $400 \mathrm{~nm}$ TTX from those recorded in the absence of TTX. The data were filtered at $1 \mathrm{kHz}$, and peak inward currents recorded during the ramp protocol were normalized to the maximum peak sodium current recorded from the same oocyte during a separate voltagedependent activation protocol described above.

Computational model. To determine the physiological effects of the changes in sodium channel kinetics caused by the D1866Y mutation, Hodgkin-Huxley-type conductance-based models of spiking neurons were constructed using the NEURON simulation software (Hines and Carnevale, 1997). Single-compartment models of neuronal soma were constructed, and sodium and delayed rectifier potassium channels were included as described previously (Spampanato et al., 2004).

The models included wild-type $\mathrm{Na}_{\mathrm{v}} 1.1$ or D1866Y mutant channels with kinetics and voltage dependencies characterized in this study and delayed rectifier $\mathrm{K}^{+}$channels with kinetics similar to those used previously (Spampanato et al., 2004). In all cases, the modeled sodium channel kinetics represent those that were determined during coexpression of the $\beta 1$ subunit. Experimentally determined voltage-dependent activation was fit with the following equation:

$$
m_{\infty}^{3}(V)=\left(1 /\left(1+\exp \left(\left(-e \times z \times\left(V-V_{1 / 2}\right)\right) / k T\right)\right)\right)^{3},
$$

where $e$ is the elementary charge, $k$ is the Boltzmann's constant, $T$ is the absolute temperature, $V_{1 / 2}$ is the half-maximal activation voltage, and $z$ is the apparent charge movement for steady-state activation $\left(m_{\infty}\right)$. The $V_{1 / 2}$ and $z$ values for $m_{\infty}$ were then used to model sodium current activation for both mutant and wild-type channels as follows:

$$
m_{\infty}(V)=1 /(1+\exp (-0.03937 \times 3.9 \times(V+30.6))) .
$$

The wild-type steady-state fast inactivation and kinetics were described using the following equations:

$$
\begin{gathered}
h_{\infty}(V)^{N a v 1.1}=1 /(1+\exp ((V+41.52) / 8.14)), \\
\tau_{\mathrm{h}}(V)^{N a v 1.1}=23.12 \times \exp \left(-0.5 \times((V+77.58) / 43.92)^{2}\right) .
\end{gathered}
$$

The D1866Y mutation altered the steady-state fast inactivation and the time constant of fast inactivation so that those differences were modeled as follows:

$$
\begin{gathered}
h_{\infty}(V)^{D 1866 Y}=1 /(1+\exp ((V+31.74) / 6.61)), \\
\tau_{\mathrm{h}}(V)^{D 1866 Y}=19.62 \times \exp \left(-0.5 \times((V+57.82) / 40.66)^{2}\right) .
\end{gathered}
$$

The sodium currents were described with activation and fast and slow inactivation as follows:

$$
I_{\mathrm{Na}}=g_{\mathrm{Na}} \times\left(V-E_{\mathrm{Na}}\right),
$$

where $g_{\mathrm{Na}}=g_{\mathrm{Na}}{ }^{\max } m^{3} \times h \times s, E_{\mathrm{Na}}=50 \mathrm{mV}$, and $g_{\mathrm{Na}}{ }^{\max } m^{3}=200$ $\mathrm{mS} / \mathrm{cm}^{2}$.

Yeast two-hybrid experiments. C-terminal fragments of the $\operatorname{SCN} 1 \mathrm{~A}(\alpha)$, $\operatorname{SCN} 1 \mathrm{~B}(\beta 1)$, SCN2B $(\beta 2)$, and SCN3B $(\beta 3)$ cDNAs were generated by PCR amplification from rat cDNA clones using primers that incorporated in-frame restriction sites for cloning. BamHI-XhoI fragments of mutant and wild-type SCN1A were cloned into the vector pACTII (Clontech, Cambridge, UK). NcoI-BamHI fragments containing the $\beta$ subunit fragment were cloned into the vector pAS-CYH2. Clones were transformed singly or in pairwise combinations into yeast strain Y190. $\beta$-Galactosidase activity was detected with a colony-lift filter assay
(Breeden and Nasmyth, 1985; Ausubel et al., 1987). As a positive control, we cotransfected the plasmids pACT2-ankyrin (Drosophila) and pASCYH2-neuroglian (180 kDa isoform), previously shown to interact in the yeast two-hybrid assay (Dubreuil et al., 1996). A negative control was provided by the sodium channel $\beta 2$ cytoplasmic domain (see Results).

Mammalian expression constructs. The wild-type SCN1A C-terminal expression construct (see Fig. 7A) contained the 19 residue signal sequence from the $\beta 1$ subunit, the 9 amino acid hemagglutinin (HA) epitope, the 20 amino acid linker RILQSTVPRARDPPVAIKTT, and residues P1759 through K2009 containing the D4S6 transmembrane segment and the entire C-terminal cytoplasmic domain. The mutant construct carried the D1866Y substitution. The $\beta 1$ and $\beta 1_{\text {STOP }}$ constructs were described previously (McEwen et al., 2004).

Immunoprecipitation. Forty-eight hours before immunoprecipitation, 1610 Chinese hamster lung fibroblasts were transiently transfected with 2 $\mu \mathrm{g}$ of plasmid DNA from constructs $\beta 1, \beta 1_{\text {STOP }}, \mathrm{Na}_{\mathrm{v}} 1.1$, and/or D1866Y (see Fig. 7). Non-immune control sera or $\beta 1_{\mathrm{EX}}$ antibodies directed against the extracellular domain of the $\beta 1$ subunit (Malhotra et al., 2000) were incubated on a rotator at $4^{\circ} \mathrm{C}$ overnight with protein A-Sepharose beads (Sigma, St. Louis, MO) in dilution buffer (60 mm Tris/HCl, pH 7.5, $180 \mathrm{~mm} \mathrm{NaCl}, 0.75 \%$ Triton X-100, and 6 mm EDTA) containing Complete Protease Inhibitors (Roche). Transfected cells were harvested and solubilized in $500 \mu \mathrm{l}$ of dilution buffer. Soluble fractions were incubated with antibody-containing beads on a rotator at $4^{\circ} \mathrm{C}$ for $6 \mathrm{hr}$, then washed and resuspended as described previously (McEwen et al., 2004). Proteins were separated on $18 \%$ SDS-PAGE gradient gels (Bio-Rad, Hercules, CA), electrophoretically transferred to nitrocellulose (Amersham Biosciences, Piscataway, NJ), and probed with anti-HA.11 antibody (1:1000; Covance, Princeton, NJ). Blots were probed with anti-rabbit secondary antibody conjugated to horseradish peroxidase and visualized using the West Dura enhanced chemiluminescence detection system (Pierce, Rockford, IL).

\section{Results}

\section{Dominant inheritance of GEFS + in an Italian pedigree}

The pedigree of a small family with four affected members is presented in Figure $1 \mathrm{~A}$. The clinical features of each affected individual are described in Table 1 . Three affected individuals experienced febrile seizures persisting beyond 6 years of age, followed by onset of non-febrile seizures after the age of 6 . One affected individual (III-1) experienced afebrile myoclonic and atonic-astatic seizures beginning at the age of 3 and developed progressive learning disabilities. Her clinical and EEG features were consistent with myoclonic-astatic epilepsy, also known as Doose syndrome (Doose, 1989, 1992), one of the most severe seizure phenotypes identified in families with GEFS + . The fourth affected individual (III-2) continues to have febrile seizures without afebrile seizures, consistent with her young age.

\section{Identification of the D1866Y mutation in SCN1A}

Because the family was too small for linkage analysis, SCN1A was screened as a candidate gene based on the clinical diagnosis of GEFS + . The exons of SCN1A were amplified from genomic DNA and analyzed by conformation-sensitive gel electrophoresis as described previously (Escayg et al., 2000). All of the affected individuals appeared to be heterozygous for wild-type and variant PCR products from exon 24 (Fig. $1 B$ ). This was confirmed by amplification and sequencing of the PCR products, which identified a $G$ to $T$ nucleotide substitution that changes the amino acid sequence of the protein (Fig. $1 B$ ). This mutation was not detected in a group of 201 unaffected controls (Escayg et al., 2001).

The substitution of tyrosine for aspartate at position 1866 introduces a nonconservative change within an evolutionarily 
A

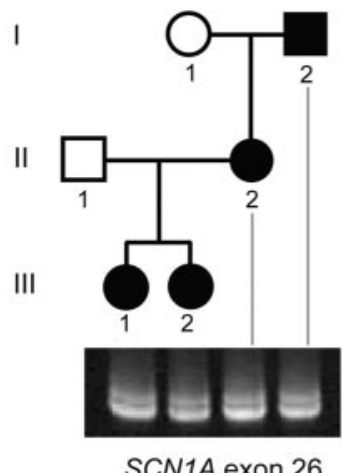

C

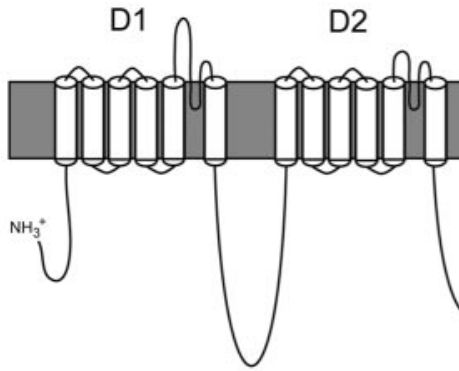

D1866Y

SCN1A

SCN2A

SCN $3 A$

SCN 4 A

SCN5A

SCN6A

SCN8A

SCN9A

SCN10A

SCN11A

C. pyrrhogaster (Newt)

D. rerio (Zebrafish)

L. opalescens (Squid)

D. melanogaster (Fruit Fly)

C. capillata (Jelly Fish)
B

G A T C

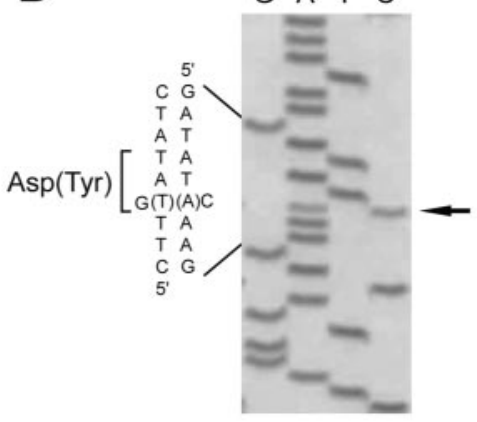

D3

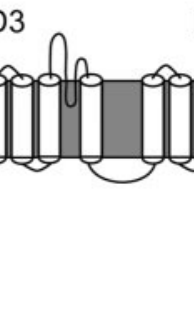

D4

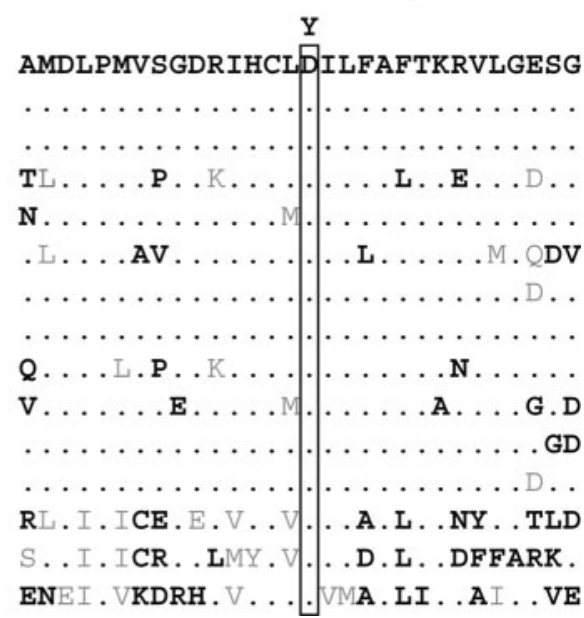

Figure 1. Identification of an SCN1A missense mutation in an Italian GEFS + pedigree. A, DNA was obtained from four affected individuals in three generations. Conformation-sensitive gel electrophoresis of an internal fragment of exon 24 generated two bands from affected individuals. $B$, Sequence of exon 24 revealed heterozygosity for a $G$ to $T$ substitution that changes an aspartate residue to tyrosine (D1866Y). C, D1866Y is located in the C-terminal cytoplasmic domain of SCN1A. D, Evolutionary conservation of aspartate D1866. This residue is invariant in all members of the human gene family, SCN1A to SCN11A, and in homologous invertebrate sodium channels. GenBank accession numbers are from Escayg et al. (2001).

conserved segment of the cytoplasmic C-terminal domain of the protein (Fig. 1C,D). The conservation of this residue in paralogous human channels and all sequenced invertebrate sodium channels suggests that it is essential for channel function.

The D1866Y mutation does not alter the voltage dependence of sodium channel activation

To determine the effects of the D1866Y mutation on the functional properties of the sodium channel, the mutation was introduced into the previously described orthologous full-length rat $\mathrm{Na}_{\mathrm{v}} 1.1$ cDNA clone (Smith and Goldin, 1998; Spampanato et al., 2003). The biophysical properties of the mutant channels were characterized using the Xenopus oocyte expression system, for the following reasons. First, it was possible to control the ratio of $\alpha$ to $\beta 1$ subunit protein in oocytes by injection of fixed amounts of RNA encoding each subunit, which cannot be done when using transfection into mammalian cells. Second, the $\beta 1$ subunit has a clear and easily quantifiable effect on the properties of $\alpha$ subunit sodium channels in oocytes, so that we could reliably determine whether the $\alpha$ subunit mutation altered modulation by $\beta 1$. Third, the data could be directly compared with our previous results for three other GEFS + mutations with respect to both the effects on sodium channel properties and the predicted effects on neuronal firing using a computational model (Spampanato et al., 2001, 2003, 2004). It is important to note that although the oocyte expression system provides a powerful means to determine biophysical differences between mutant and wild-type channels, there have been functional differences as well as similarities between observations in oocytes and in mammalian-transfected cells for some mutants (Spampanato et al., 2001, 2003; Lossin et al., 2002). It remains to be shown that any of the heterologous systems accurately represent channel function in the native environment of the neuron. For these experiments, the channels were expressed in the absence and presence of the $\beta 1$ subunit. The $\beta 2$ subunit was not included because its presence did not significantly affect any properties of the wild-type channel (Smith and Goldin, 1998). The fast-gated properties of the mutant channels were compared with those of the wild-type $\mathrm{Na}_{\mathrm{v}} 1.1$ channels using the cut-open oocyte voltage clamp.

Table 1. Clinical features of affected individuals from the family with GEFS+

\begin{tabular}{|c|c|c|c|c|c|}
\hline \multirow[b]{2}{*}{ Affected individual } & \multicolumn{2}{|c|}{ Febrile seizures } & \multicolumn{2}{|l|}{ Afebrile seizures } & \multirow[b]{2}{*}{ Therapy } \\
\hline & Age of onset & Last seizure & Age of last seizure & Seizure type & \\
\hline I-2, male, age 69 & 2 years & 12 years & 60 years & General tonic clonic & PB (100 mg/d) \\
\hline II-2, female, age 32 & 2 years & 12 years & 31 years & General tonic clonic & VPA $(500 \mathrm{mg} / \mathrm{d})$ \\
\hline III-1, female, age 7 & 8 months & Continuing & 7 years & $\begin{array}{l}\text { Myoclonic and atonic with learning difficulties } \\
\text { and behavioral problems }\end{array}$ & VPA $(800 \mathrm{mg} / \mathrm{d})$ \\
\hline III-2, female, age 3 & 8 months & Continuing & 3 years & $N / A$ & None \\
\hline
\end{tabular}


Because shifts in the voltage dependence of activation are a common diseasecausing mechanism underlying known sodium channelopathies (Cummins et al., 1993; Mitrovic et al., 1995; Green et al., 1998; Rook et al., 1999; Smith and Goldin, 1999), including three mutations associated with GEFS+ (Lossin et al., 2003; Spampanato et al., 2003), we first characterized the voltage dependence of channel activation. Peak current amplitudes were recorded as described in Materials and Methods and fit with a two-state Boltzmann equation (Fig. $2 A$ ) for mutant and wild-type channels in the absence and presence of the $\beta 1$ subunit. The voltage dependence of activation for the D1866Y mutant was not significantly different from that of wild-type $\mathrm{Na}_{\mathrm{v}} 1.1$ when expressed as the $\alpha$ subunit alone or when coexpressed with the $\beta 1$ subunit. There were no significant differences in either the $V_{1 / 2}$ or the slope values between mutant and wild-type channels (Table 2) under either condition. In addition, the presence of the $\beta 1$ subunit did not significantly alter the voltage dependence of activation, consistent with previously published data (Smith and Goldin, 1998).

\section{The D1866Y mutation alters sodium channel inactivation}

Rapid voltage-dependent inactivation is critical for proper sodium channel function. Functional studies have identified the cytoplasmic $\mathrm{C}$ terminus of several sodium channel isoforms as playing a modulatory role in the voltage dependence of fast inactivation (An et al., 1998; Wehrens et al., 2000; Abriel et al., 2001; Deschênes et al., 2001; Mantegazza et al., 2001; Cormier et al., 2002). We therefore tested the effect of the D1866Y mutation, which is in the $\mathrm{C}$ terminus of the channel, on the voltage dependence of inactivation.

The D1866Y mutation produced an $\sim 5 \mathrm{mV}$ positive shift in the $V_{1 / 2}$ of inactivation compared with wild-type $\mathrm{Na}_{\mathrm{v}} 1.1$ when the channels were expressed as $\alpha$ subunits alone (Fig. 2A, Table 2). Coexpression of the $\beta 1$ subunit resulted in a negative shift in the voltage dependence of inactivation for both mutant and wildtype channels. However, the mutant failed to shift as far as the wild-type channel in the presence of $\beta 1$, resulting in a larger difference of $10 \mathrm{mV}$ in the $V_{1 / 2}$ of inactivation between D1866Y and wild-type channels in the presence of $\beta 1$. The effect of this difference can be seen clearly by comparing normalized current traces from mutant and wild-type channels depolarized to -40 $\mathrm{mV}$, approximately the $V_{1 / 2}$ for wild-type $\mathrm{Na}_{\mathrm{v}} 1.1$ coexpressed with $\beta 1$ (Fig. $2 B$ ). Under these conditions, the mutant D1866Y

A
Voltage Dependence $(\alpha)$

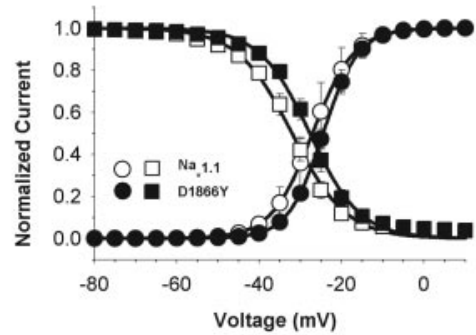

B
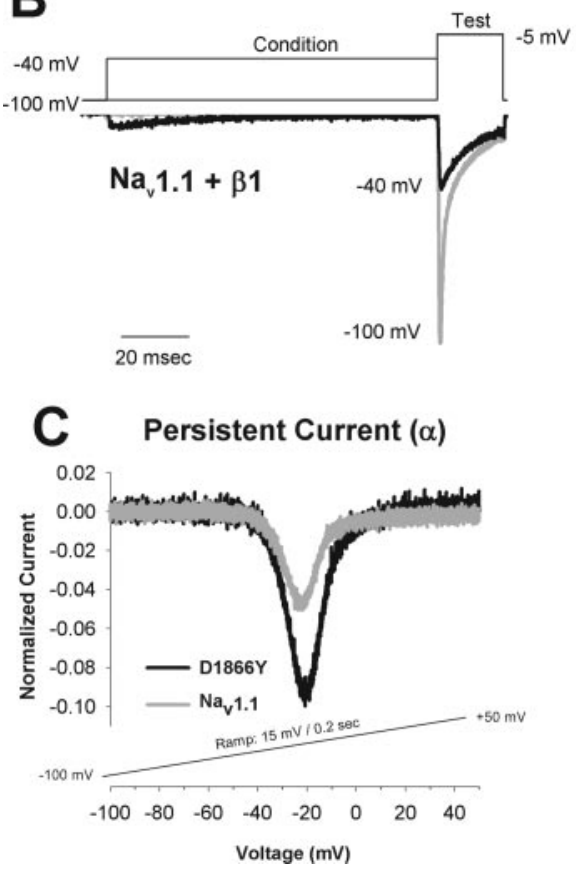

Voltage Dependence $(\alpha+\beta 1)$

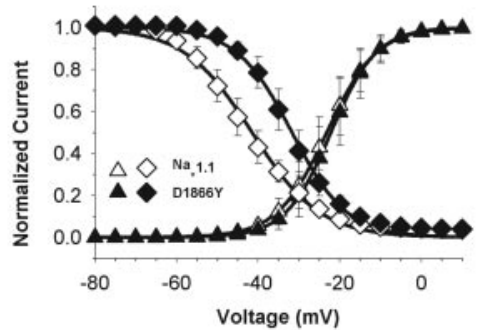

Figure 2. Voltage-dependent gating of wild-type $\mathrm{Na}_{\mathrm{v}} 1.1$ and D1866Y mutant channels in the absence and presence of the $\beta 1$ subunit. $A$, The voltage dependence of activation was determined for the wild-type $\mathrm{Na}_{\mathrm{v}} 1.1$ (open symbols) and D1866Y (solid symbols) mutant channels expressed as $\alpha$ subunits alone (circles) or as $\alpha$ plus $\beta 1$ (triangles). Sodium currents were recorded from a holding potential of $-100 \mathrm{mV}$ by a series of depolarizations to potentials between -95 and $+50 \mathrm{mV}$ in $5 \mathrm{mV}$ increments. Normalized conductance values were calculated by dividing the peak current amplitudes by the driving force at each potential and normalizing to the maximum conductance. The values shown are means, and the error bars are SDs. The data were fit with a two-state Boltzmann equation, and the parameters of the fits are shown in Table 2. The voltage dependence of inactivation was determined for the wild-type $\mathrm{Na}_{v} 1.1$ (open symbols) and D1866Y (solid symbols) mutant channels expressed as $\alpha$ subunits alone (squares) or as $\alpha$ plus $\beta 1$ (diamonds). The voltage dependence of inactivation was determined using a two-step protocol in which a conditioning pulse was applied from a holding potential of $-100 \mathrm{mV}$, consisting of $100 \mathrm{msec}$ depolarizations to a range of potentials from -100 to $+15 \mathrm{mV}$ in $5 \mathrm{mV}$ increments, followed by a test pulse to $-5 \mathrm{mV}$. The peak current amplitude during each test pulse was normalized to the peak current amplitude during the first test pulse and plotted as a function of the conditioning pulse potential. The values shown are means, and the error bars are SDs. The data were fit with a two-state Boltzmann equation, and the parameters of the fits are shown in Table 2. B, A sample voltage protocol consisting of conditioning pulses to -100 and $-40 \mathrm{mV}$ (approximately the $V_{1 / 2}$ of wild-type inactivation), followed by a test pulse to $-5 \mathrm{mV}$. The corresponding normalized sodium currents recorded during the protocol are shown for $\mathrm{Na}_{v} 1.1$ plus $\beta 1$ and D1866Y plus $\beta 1$. A comparison of the current amplitudes demonstrates that the mutant channel carried approximately twofold more current than the wild-type channel after a depolarization to $-40 \mathrm{mV}$. C, Persistent current was recorded using a slow depolarizing voltage ramp of $15 \mathrm{mV}$ per $200 \mathrm{msec}$ applied from a holding potential of -100 to $+50 \mathrm{mV}$. The traces shown are representative TTX-sensitive sodium currents resulting from the subtraction of currents recorded before and after application of $400 \mathrm{~nm}$ TTX. In each case, the peak ramp currents were normalized to the maximum peak sodium current for that oocyte. The average relative peak persistent currents recorded for each condition were as follows: $\mathrm{Na}_{v} 1.1(n=6), 0.045 \pm 0.003 ; \mathrm{D} 1866 \mathrm{Y}(n=5), 0.098 \pm 0.009 ; \mathrm{Na}_{\mathrm{v}} 1.1$ plus $\beta 1(n=8), 0.037 \pm$ 0.007 ; D1866Y plus $\beta 1(n=8), 0.060 \pm 0.006$.

channels demonstrated twofold more current than the wild-type channels.

The shift in voltage dependence of inactivation should affect the window current, which is the region of overlap between the curves for the voltage dependence of activation and inactivation. The window current represents a voltage region in which sodium 
Table 2. Parameters of voltage-dependent gating

\begin{tabular}{|c|c|c|c|c|c|c|}
\hline \multirow[b]{2}{*}{ Channel } & \multicolumn{3}{|l|}{ Activation } & \multicolumn{3}{|l|}{ Inactivation } \\
\hline & $V_{1 / 2}(\mathrm{mV})$ & $z\left(e_{0}\right)$ & $n$ & $V_{1 / 2}(\mathrm{mV})$ & $a(\mathrm{mV})$ & $n$ \\
\hline $\mathrm{Na}_{\mathrm{v}} 1.1$ & $-27.0 \pm 2.8$ & $5.4 \pm 0.5$ & 5 & $-32.0 \pm 1.3$ & $6.6 \pm 0.5$ & 5 \\
\hline D1866Y & $-24.5 \pm 0.8$ & $6.1 \pm 0.8$ & 4 & $-27.7 \pm 1.0^{a}$ & $6.1 \pm 0.7$ & 5 \\
\hline $\mathrm{Na}_{\mathrm{v}} 1.1$ plus $\beta 1$ & $-23.2 \pm 3.5$ & $4.4 \pm 0.3$ & 5 & $-41.5 \pm 2.4$ & $8.1 \pm 0.7$ & 5 \\
\hline D1866Y plus $\beta 1$ & $-22.1 \pm 3.6$ & $4.9 \pm 0.3$ & 5 & $-31.7 \pm 2.4^{b}$ & $6.6 \pm 0.4^{b}$ & 5 \\
\hline
\end{tabular}

${ }^{a}$ Statistically significant difference from wild-type $\mathrm{Na}_{\mathrm{v}} 1.1 \alpha$ alone at $p<0.001$.

${ }^{b}$ Statistically significant difference from wild-type $\mathrm{Na}_{\mathrm{v}} 1.1 \alpha$ plus $\beta 1$ at $p<0.001$.

channels can continue to open because some channels are activated and not all of the channels are inactivated. Therefore, sodium channels can remain active in the voltage region of the window current, resulting in a persistent current that can cause seizure activity (Kearney et al., 2001). Theoretical analysis of the voltage dependencies presented in Figure $2 \mathrm{~A}$ suggested that the D1866Y mutant channels would be capable of maintaining a larger window current than wild-type $\mathrm{Na}_{\mathrm{v}} 1.1$ channels over a similar voltage range. This prediction was tested using a slowvoltage ramp protocol in which the oocytes were depolarized from a holding potential of -100 to $+50 \mathrm{mV}$ at a rate of $15 \mathrm{mV}$ per $200 \mathrm{msec}$. In both the absence and presence of the $\beta 1$ subunit, the D1866Y mutant channels produced nearly twofold more persistent current than wild-type $\mathrm{Na}_{\mathrm{v}} 1.1$ (Fig. $2 C$ ), confirming what was predicted based on the observed voltage dependencies.

To quantify the kinetics of inactivation, current traces recorded in a manner similar to that described for the voltage dependence of activation were fit with either a single-exponential or a double-exponential equation. The D1866Y mutant channels inactivated with kinetics that were similar to those of the wildtype channels when expressed as $\alpha$ subunits alone (Fig. 3A). However, coexpression of the $\beta 1$ subunit produced a significantly slower fast time constant $\left(\tau_{\text {Fast }}\right)$ of inactivation for the mutant channels compared with the wild-type channels between -15 and $+25 \mathrm{mV}(p \leq 0.013)$. The percentage of current inactivating with $\tau_{\text {Fast }}$ and the percentage of steady-state noninactivating current were not different between the mutant and wild-type channels (data not shown). The difference in the kinetics of inactivation can be seen clearly by comparing normalized current traces recorded during single depolarizations to $-10 \mathrm{mV}$ (Fig. 3B). The slower kinetics of inactivation produced by the D1866Y mutation was a specific failure of the $\beta 1$ subunit to fully modulate the mutant channels because there were no differences in the kinetics of inactivation between the mutant and wild-type channels when expressed as $\alpha$ subunits alone.

\section{The D1866Y mutation reduces sodium channel use dependence}

Inactivated sodium channels must first recover from the inactivated state to the closed state before they can open in response to a threshold depolarization. This latency period dictates how rapidly the channels can participate in the firing of an action potential and is therefore a key regulatory element of neuronal excitability. Changes to the intrinsic firing properties of neurons that result in an increase in excitability are known to cause seizure activity (Dichter, 1991, 1994). Separate disease-causing mutations in $\mathrm{Na}_{\mathrm{v}} 1.4$ and $\mathrm{Na}_{\mathrm{v}} 1.5$, as well as our previously published data for the GEFS + mutation $\mathrm{R} 1648 \mathrm{H}$ in $\mathrm{Na}_{\mathrm{v}} 1.1$, demonstrate that more rapid recovery from inactivation can result in sodium channel-mediated hyperexcitability (Hayward et al., 1996; Q. Chen et al., 1998; Spampanato et al., 2001). We therefore analyzed the effects of the D1866Y mutation on recovery from inac- tivation in the absence and presence of the $\beta 1$ subunit (Fig. $4 A$, Table 3), as described in Materials and Methods.

The D1866Y mutant channels recovered with a time course that was similar to that of wild-type $\mathrm{Na}_{\mathrm{v}} 1.1$ when the channels were expressed as $\alpha$ subunits alone. Both mutant and wild-type channels required $\sim 3000 \mathrm{msec}$ to fully recover from inactivation. Coexpression of the $\beta 1$ subunit increased the rate of recovery for mutant and wild-type channels so that both reached full recovery in $<200 \mathrm{msec}$. Although both channels reached full recovery at a similar time, recovery of the D1866Y mutant channels was more rapid during the slow phase (Table 3 ).

To determine whether the D1866Y mutant channels were capable of increased firing during repetitive depolarizations, we examined the frequency dependence of the peak sodium current in response to a series of rapid depolarizations (Spampanato et al., 2003). This protocol evaluates both recovery from inactivation and the rate of entry into the inactivated state. If there is insufficient time for complete recovery between each depolarization, then the magnitude of the current will decrease with successive depolarizations as a result of channels accumulating in the inactivated state. Frequency dependence was examined at $39 \mathrm{~Hz}$ in the absence and presence of the $\beta 1$ subunit (Fig. $4 B$ ). When expressed as $\alpha$ subunits alone, the D1866Y mutant channels displayed a similar use dependence to that of wild-type $\mathrm{Na}_{\mathrm{v}} 1.1$, with both channels reaching equilibrium current amplitudes that were $\sim 10 \%$ of the maximum peak current. This is not surprising based on the previous results demonstrating no significant differences in the kinetics of channel inactivation or recovery between the mutant and wild-type channels when expressed as $\alpha$ subunits alone. In the presence of the $\beta 1$ subunit, the D1866Y mutant channels maintained a higher equilibrium current $(62 \%)$ than the wild-type channels (47\%).

\section{The D1866Y mutant channels produce a hyperexcitable model neuron}

The primary effects of the D1866Y mutation were a positive shift in the voltage dependence of inactivation and a delay in the rate of fast inactivation when coexpressed with the $\beta 1$ subunit. To determine how these biophysical changes in sodium channel function might alter neuronal excitability, a conductance-based computational model was designed using the parameters determined from our experimental characterization of the mutant channels, as described in Materials and Methods.

Computational analysis of three GEFS + mutations has previously shown that each mutation had a different effect on the threshold for firing a single action potential, but all the mutations increased the propensity of the model neuron to fire multiple action potentials (Spampanato et al., 2004). When analyzed in a similar manner, the D1866Y mutation did not have any effect on the threshold for firing a single action potential (70 pA for both mutant and wild-type channels), nor did it increase the propen- 
A
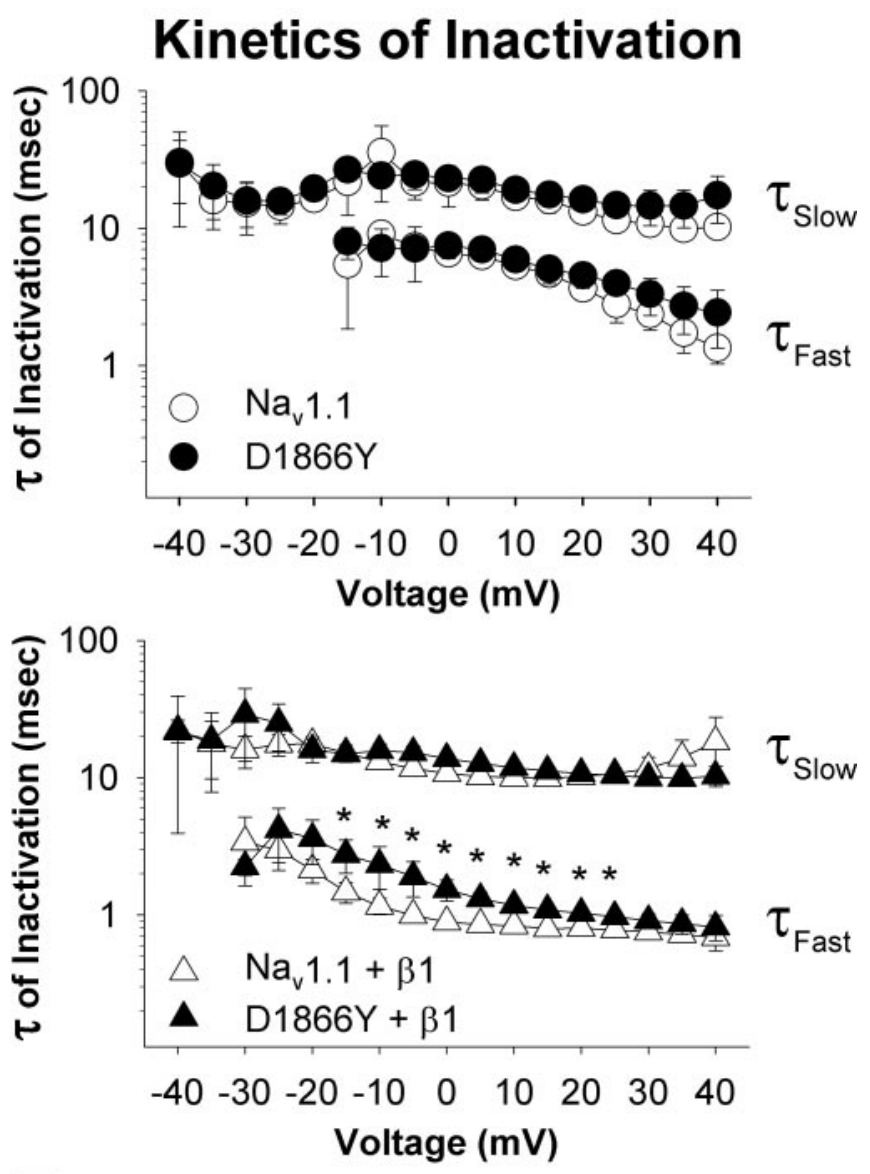

B

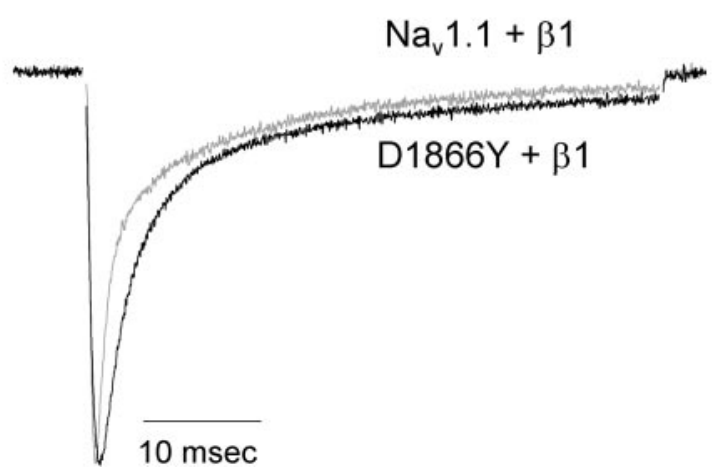

Figure 3. Kinetics of inactivation of wild-type $\mathrm{Na}_{\mathrm{v}} 1.1$ and D1866Y mutant channels in the absence and presence of the $\beta 1$ subunit. $A$, Sodium currents were recorded from oocytes expressing wild-type $\mathrm{Na}_{\mathrm{v}} 1.1$ (open symbols) or D1866Y (solid symbols) mutant channels, as described in the legend to Figure 2. Current traces were fit with either a single-exponential or a double-exponential equation as described previously (Spampanato et al., 2003). The time constants for the fast $\left(\tau_{\text {fast }}\right)$ and slow $\left(\tau_{\text {slow }}\right)$ components of inactivation are plotted on a logarithmic scale in the top panel for $\alpha$ alone (circles) and in the bottom panel for $\alpha$ plus $\beta 1$ (triangles). In all cases, the sum of the fraction of current inactivating with the $\tau_{\text {fast }}$ and $\tau_{\text {slow }}$ components is 1. This property did not differ between wild-type $\mathrm{Na}_{\mathrm{v}} 1.1$ and D1866Y mutant channels (data not shown). The values shown are means, and the error bars indicate SDs. $B$, Comparison of normalized current traces for the D1866Y mutant channels and the wild-type channels in the presence of the $\beta 1$ subunit during a depolarization from -100 to $-10 \mathrm{mV}$ demonstrates the subtle delay in fast inactivation kinetics caused by the D1866Y mutation. sity of the model neuron to fire multiple action potentials (data not shown).

The two significant effects of the D1866Y mutation were to decrease the latency between stimulus onset and action potential generation at threshold and to decrease the time between action potentials at a higher input stimulus (Fig. 5A). At the threshold stimulus of $70 \mathrm{pA}$, the D1866Y model neuron fired an action potential $\sim 5 \mathrm{msec}$ sooner than the wild-type model neuron. This effect was maintained when both mutant and wild-type channels were included in the same model neuron at a ratio of $1: 1$ $\left(\mathrm{D} 1866 \mathrm{Y}^{+/-}\right)$, which should more closely resemble the in vivo situation because GEFS + is an autosomal dominant disease. When the stimulus intensity was increased to $100 \mathrm{pA}$, both the mutant and wild-type model neurons fired three action potentials. Although the overall number of action potentials was the same, the D1866Y model neuron had a shorter spike-to-spike interval, so that all three action potentials were fired in a shorter time. The D1866Y mutation was dominant and not simply additive, because the $\mathrm{D} 1866 \mathrm{Y}^{+/-}$heterozygous neuron with a $1: 1$ channel ratio behaved more like the mutant than the wild-type model neuron.

To determine which alteration in sodium channel function was responsible for the change in neuronal firing, we constructed model neurons in which the channels had either delayed kinetics of inactivation (D1866Y- $\tau$ ) or a positive shift in the voltage dependence of inactivation (D1866Y-V). When the D1866Y- $\tau$ model neuron was activated with a threshold stimulus of $70 \mathrm{pA}$, the model neuron fired a single action potential, the timing of which was identical to that of the wild-type model neuron (Fig. $5 B)$. When the stimulus intensity was increased to $100 \mathrm{pA}$, the timing of the first and second action potentials was similar for the mutant and wild-type model neurons, but the mutant neuron did not fire a third action potential. In contrast, the model neuron with only the positive shift in the voltage dependence of inactivation (D1866Y-V) fired an action potential $\sim 5 \mathrm{msec}$ sooner than the wild-type model neuron with a stimulus of $70 \mathrm{pA}$ (Fig. 5C). Therefore, the shift in the voltage dependence of inactivation was responsible for the major difference between the D1866Y mutant and wild-type model neurons. When the D1866Y-V model neuron was stimulated with $100 \mathrm{pA}$, it generated action potentials with a shorter spike-to-spike interval than the D1866Y model neuron, which resulted in the generation of an additional action potential. This result indicates that the two changes in sodium channel function, delayed kinetics of inactivation and a positive shift in the voltage dependence of inactivation, had compensatory effects on the firing of a third action potential.

Because the D1866Y mutation produced a positive shift in the $V_{1 / 2}$ of inactivation, it was likely that the mutant model neuron would be resilient to inactivation during a subthreshold incoming stimulus that produced a sustained depolarization of the membrane potential. To determine the effects of a positive shift in membrane potential, model neurons were first injected with a subthreshold stimulus of $60 \mathrm{pA}$, which shifted the membrane potential to approximately $-53 \mathrm{mV}$, followed by an additional 10 pA current injection for $17 \mathrm{msec}$ to elicit action potentials. The conditioning stimuli was applied for $0,20,40,60$, or $80 \mathrm{msec}$, and the membrane potential was plotted from the start of the $60 \mathrm{pA}$ stimulus (Fig. 6). The wild-type model neuron failed to fire an action potential when the subthreshold depolarization was maintained for $60 \mathrm{msec}$ or longer, whereas the mutant was capable of firing an action potential regardless of the length of the conditioning depolarization. The D1866 $\mathrm{Y}^{+/-}$heterozygous model neuron behaved more like the D1866Y model neuron, demonstrating 

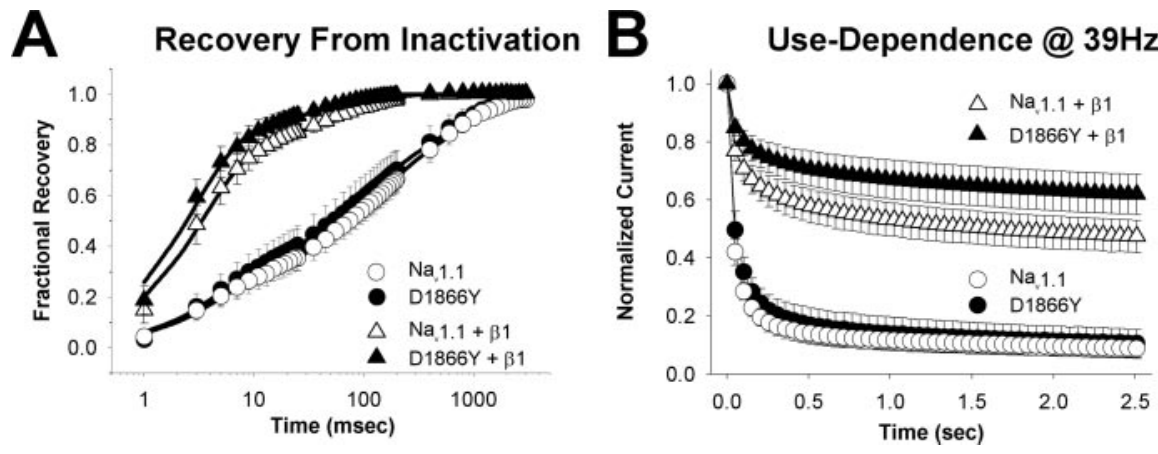

Figure 4. Recovery from fast inactivation and use dependence for wild-type $\mathrm{Na}_{\mathrm{v}} 1.1$ and D1866 Y mutant channels. A, Recovery from inactivation was determined using three two-pulse protocols for wild-type $\mathrm{Na}_{\mathrm{v}} 1.1$ (open symbols) and D1866Y (solid symbols) mutant channels expressed as $\alpha$ subunits alone (circles) or $\alpha$ plus $\beta 1$ (triangles). Each protocol was performed from a holding potential of $-100 \mathrm{mV}$ and consisted of a conditioning depolarization to $-5 \mathrm{mV}$ for $50 \mathrm{msec}$, a decreasing recovery time interval at $-100 \mathrm{mV}$, and a test depolarization to $-5 \mathrm{mV}$. The three protocols differed only in the maximum length of recovery time and the time interval by which that recovery period decreased. Fractional recovery, calculated by dividing the maximum current amplitude during the test pulse by the maximum current amplitude during the corresponding conditioning pulse, was plotted on a log scale as a function of the recovery time interval. The values shown are means, and the error bars are SDs. The data were fit with either a triple-exponential or a double-exponential equation, as described previously (Spampanato et al., 2003), and the parameters of the fits are shown in Table 3.B, Use dependence was analyzed at $39 \mathrm{~Hz}$ for wild-type $\mathrm{Na}_{\mathrm{v}} 1.1$ (open symbols) and D1866Y (solid symbols) mutant channels expressed as $\alpha$ subunits alone (circles) or $\alpha$ plus $\beta 1$ (triangles). Currents were elicited by $17.5 \mathrm{msec}$ depolarizations to $-10 \mathrm{mV}$ from a holding potential of $-100 \mathrm{mV}$. The protocol was performed for $2.56 \mathrm{sec}$, by which time the current had reached equilibrium. Peak current amplitudes were normalized to the initial peak current amplitude and plotted against the start time of the corresponding depolarization in the pulse train. The values shown are means, and the error bars are SDs.

the dominant nature of the D1866Y mutation. This trend was consistent with a subthreshold stimulus of longer than $160 \mathrm{msec}$ (data not shown).

\section{Direct interaction between the C-terminal domains of $\alpha$ and $\boldsymbol{\beta}$ subunits in yeast}

The kinetics and voltage dependence of channel inactivation demonstrate a difference in modulation of mutant and wild-type channels in the presence of the $\beta 1$ subunit. Because the D1866Y mutation is located in the cytoplasmic C-terminal portion of the $\alpha$ subunit, we hypothesized that it might be located in a domain that interacts directly with the cytoplasmic domain of the $\beta$ subunit. This possibility was tested first in the yeast two-hybrid system. Two $\alpha$ subunit fragments, corresponding to the full-length 226 amino acid C-terminal domain of SCN1A and the 41 amino acid subfragment K1846-R1886, centered on residue D1866, were cloned into the yeast expression plasmid pACTII containing the GAL4 activation domain. The 36 amino acid C terminus of the $\beta 1$ subunit, the 34 amino acid $C$ terminus of the $\beta 3$ subunit, and the 32 amino acid $C$ terminus of the $\beta 2$ subunit were cloned into plasmid pAS-CYH2 containing the GAL4 DNA-binding domain. The constructs were transformed singly or pairwise into yeast strain 190, and $\beta$-galactosidase activity was assayed. Cotransformation of the 226 or 41 residue $\alpha$ subunit fragment in combination with the $\mathrm{C}$ terminus of $\beta 1$ or $\beta 3$ resulted in $\beta$-galactosidase expression (Table 4). $\beta$-Galactosidase staining appeared after $1-3 \mathrm{hr}$ in colonies expressing the $\beta 3$ subunit and also in the positive control that consisted of the interacting fragments from ankyrin and neuroglian (Dubreuil et al., 1996). $\beta$-Galactosidase staining appeared after $8-16 \mathrm{hr}$ in colonies expressing the $\beta 1$ subunit. As predicted by the sequence divergence, no interaction was detected with the $\beta 2$ subunit, which served as a negative control (Table 4). The D1866Y mutation did not prevent interaction with the $\beta$ subunits in this assay (Table 4 ). This result is not inconsistent with the kinetic analysis, which demonstrated some modulation of the mutant channel by $\beta 1$.

\section{D1866Y disrupts the interaction}

between the $\mathrm{Na}_{\mathrm{v}} 1.1 \mathrm{C}$ terminus and $\beta 1$ in mammalian cells

To confirm the interaction between the $\mathrm{Na}_{\mathrm{v}} 1.1$ C-terminal domain and $\beta 1$ in a mammalian cell, we cotransfected into Chinese hamster lung fibroblasts the fulllength $\beta 1$ subunit and an HA-tagged $\alpha$ subunit construct encoding the D4S6 transmembrane segment and complete C-terminal cytoplasmic domain of SCN1A (Fig. 7A). The wild-type and mutant $\alpha$ subunit constructs were expressed at comparable levels in the transfected cells (Fig. 7B, lanes 5,6). Immunoprecipitation was performed with $\beta 1_{\mathrm{EX}}$ antiserum directed toward the extracellular domain of the $\beta 1$ subunit (Malhotra et al., 2000). Coimmunoprecipitation of the wild-type $\alpha$ and $\beta$ constructs was detected on Western blots probed with anti-HA serum (Fig. $7 B$, lane 1). When the D1866Y mutant was substituted for the wild-type $\alpha$ subunit fragment, the amount of coimmunoprecipation was greatly reduced (Fig. $7 B$, lane 2). Substitution of the $\beta 1$ stop construct lacking the C-terminal cytoplasmic domain prevented coimmunoprecipitation of the $\alpha$ subunit fragments (Fig. 7B, lanes 3,4). The data demonstrate a direct interaction between the cytoplasmic C-terminal domains of the sodium channel $\alpha$ and $\beta 1$ subunits. The mutation D1866Y weakens this interaction, demonstrating a novel molecular mechanism of disease.

\section{Discussion}

The clinical features of the affected individuals in this small Italian pedigree were consistent with the diagnosis of GEFS + . The most common cause of GEFS + is mutation of the sodium channel $\alpha$ subunit gene SCN1A. We identified a novel SCN1A mis-

Table 3. Kinetics of recovery from fast inactivation

\begin{tabular}{|c|c|c|c|c|c|c|c|}
\hline \multirow[b]{3}{*}{ Channel } & \multicolumn{7}{|c|}{ Recovery from inactivation } \\
\hline & \multicolumn{2}{|c|}{$\underline{\tau_{1}}$} & \multicolumn{2}{|l|}{$\underline{\tau_{2}}$} & \multicolumn{3}{|l|}{$\tau_{3}$} \\
\hline & Milliseconds & Percentage & Milliseconds & Percentage & Milliseconds & Percentage & $n$ \\
\hline D1866Y & $5.2 \pm 1.4$ & $31 \pm 5$ & $96.8 \pm 34.0$ & $36 \pm 3$ & $742.2 \pm 241.0$ & $33 \pm 3$ & 5 \\
\hline $\mathrm{Na}_{\mathrm{v}} 1.1$ plus $\beta 1$ & $3.5 \pm 0.7$ & $80 \pm 3$ & $74.1 \pm 13.7$ & $20 \pm 3$ & $\mathrm{ND}^{a}$ & $\mathrm{ND}^{a}$ & 5 \\
\hline D1866Y plus $\beta 1$ & $2.8 \pm 0.5$ & $84 \pm 3$ & $42.8 \pm 12.1^{b}$ & $16 \pm 3$ & $\mathrm{ND}^{a}$ & $\mathrm{ND}^{a}$ & 5 \\
\hline
\end{tabular}

${ }^{a}$ Not determined because the recovery from inactivation of these channels was best fit with a double-exponential equation.

${ }^{b}$ Statistically significant difference from wild-type $\mathrm{Na}_{\mathrm{v}} 1.1 \alpha$ plus $\beta 1$ at $p<0.01$. 
70 pA Threshold

A

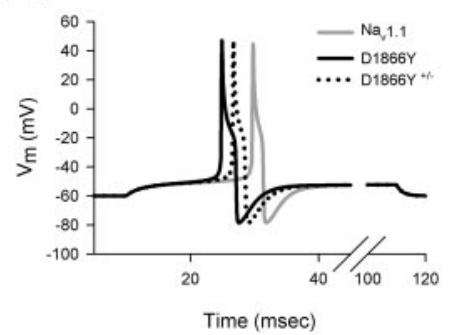

B
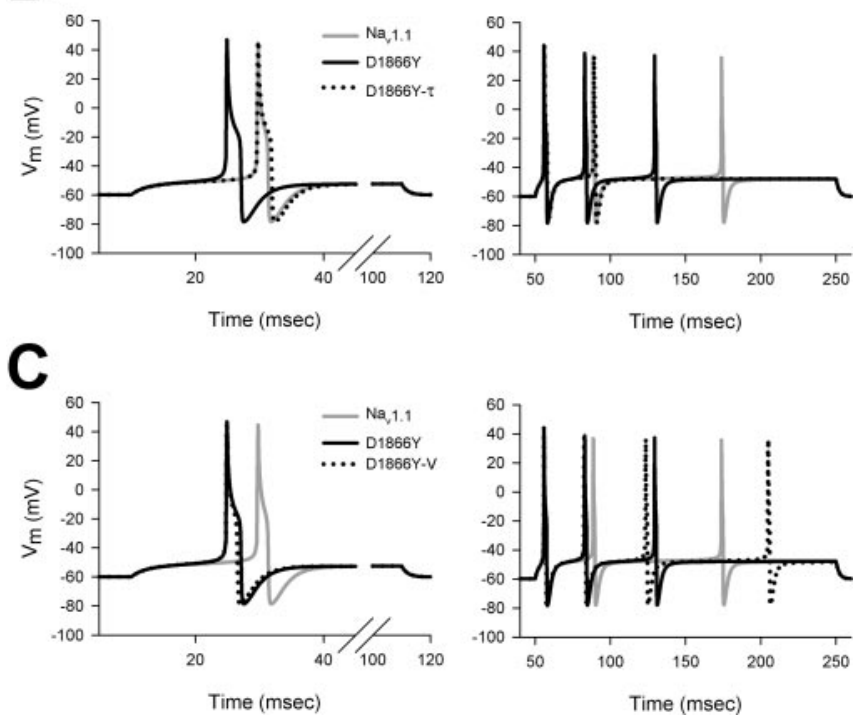

Figure 5. D1866Y mutant channels produce a hyperexcitable model neuron. The kinetics of the D1866Y mutant and wild-type $\mathrm{Na}_{\mathrm{v}} 1.1$ channels were defined using a conductance-based Hodgkin and Huxley model and the NEURON simulation software. The D1866Y mutant model neuron contained D1866Y mutant channels that differed from wild-type channels because of a positive shift in the voltage dependence of inactivation and delayed kinetics of inactivation, as shown in the previous figures. A, At a threshold stimulus (70 pA), the D1866Y mutant model neuron (black line) fired a single action potential with a shorter onset delay than the wild-type $\mathrm{Na}_{\mathrm{v}} 1.1$ model neuron (gray line). When the population of channels was mixed at a 1:1 ratio (D1866 $^{+/-}$; black dotted line), the mutant channels displayed a dominant effect, resulting in early generation of a single action potential. This effect is more pronounced at an increased stimulus intensity of $100 \mathrm{pA}$. B, When the delayed kinetics of the D1866Y mutation were modeled independently of the voltage dependence of inactivation (D1866Y- $\tau$; black dotted line), the mutant model neuron fired an action potential at threshold with timing that was comparable with that of the wild-type $\mathrm{Na}_{\mathrm{v}} 1.1$ model neuron. When the stimulus intensity was increased to $100 \mathrm{pA}$, the D1866Y- $\tau$ model neuron continued to behave in a manner similar to the wild-type neuron, but it failed to fire a third action potential. C, Independent modeling of the positive shift in the voltage dependence of inactivation caused by the D1866Y mutation (D1866Y-V; black dotted line) demonstrated that this effect was sufficient to cause the early onset of an action potential at a threshold stimulus. When the stimulus intensity was increased to $100 \mathrm{pA}$, the D1866Y-V model neuron produced more rapid action potentials resulting in generation of an additional action potential.

sense mutation, D1866Y, in the affected individuals of this family. The extensive evolutionary conservation of residue D1866 in vertebrate and invertebrate channels (Fig. 1) suggests that this residue is essential for proper channel function. This variant was not previously observed in a screen of several hundred epilepsy patients and controls (Escayg et al., 2000, 2001). In addition to GEFS +, a mild, inherited form of epilepsy, mutations in SCN1A have also been identified in the disorder severe myoclonic epilepsy of infancy (SMEI). More than 100 de novo mutations of SCN1A have been identified in sporadic cases of SMEI in Europe and Japan (Fujiwara et al., 2003; Wallace et al., 2003). Many of the SMEI mutations are null alleles, demonstrating that haploinsufficiency for $S C N 1 A$ results in a severe phenotype. A small number of SCN1A mutations have been identified in other seizure syndromes. The SCN1A-related epilepsies may be considered as a single gene disorder caused by a large number of very rare alleles (Pritchard, 2001). It is not clear whether mild alleles of SCN1A also contribute to common polygenic types of epilepsy.

The D1866Y mutation altered the voltage dependence and kinetics of fast sodium channel gating (Figs. 2-4) but had no effect on the slow gated properties (data not shown). The primary effect of the mutation that is likely to cause hyperexcitability is the $10 \mathrm{mV}$ positive shift in the voltage dependence of inactivation when coexpressed with the $\beta 1$ subunit, which consequently increased the persistent current through the mutant channels. A similar shift in the voltage dependence of inactivation was observed for the GEFS +1 mutation $\mathrm{C} 121 \mathrm{~W}$ in the $\beta 1$ subunit (Meadows et al., 2002). In contrast, hippocampal neurons from epileptic $\beta 1$ knock-out mice do not display a change in voltagedependent sodium channel gating, although this could be attributable to the changes in sodium channel isoform expression reported in these knock-out mice (C. Chen et al., 2004).

Changes in the voltage dependence of sodium channel inactivation have previously been seen after the onset of spontaneous seizure activity, but a clear cause-and-effect relationship has not been established. In multiple animal models of spontaneous seizures, the voltage dependence of sodium current inactivation in hippocampal CA1 pyramidal and dentate granule neurons was shifted toward depolarized potentials, resulting in increased sodium channel availability and window current (Vreugdenhil et al., 1998; Gu et al., 2001; Ketelaars et al., 2001; Ellerkmann et al., 2003). $\mathrm{Na}_{\mathrm{v}} 1.1$ is known to be expressed in the adult hippocampus and dentate gyrus and could therefore play a critical roll in regulating the voltage-dependent sodium currents in these cells (Westenbroek et al., 1989; Furuyama et al., 1993; Black et al., 1994; Whitaker et al., 2000; Novakovic et al., 2001). A positive shift in the voltage dependence of sodium channel inactivation should result in a larger population of sodium channels that are available to open at or near the resting membrane potential. This increase in the availability of channels remaining in the closed state is expected to increase the probability that incoming stimuli will result in the firing of an action potential. The increased probability of firing an action potential in response to incoming stimuli could be further exacerbated by the increased persistent current and the small delay in the kinetics of inactivation produced by the D1866Y mutation. This model for the action of the D1866Y mutation is consistent with the observation that many anti-epileptic drugs have the opposite effect, shifting the voltage dependence of inactivation in the negative direction (Köhling, 2002). These drugs include valproate, lamotrigine, and carbamazepine (Xie et al., 1995; Kuo and Lu, 1997; Kuo et al., 1997; Zona and Avoli, 1997; Kuo, 1998; Vreugdenhil et al., 1998; Pugsley et al., 1999; Reckziegel et al., 1999; Vreugdenhil and Wadman, 1999; Siep et al., 2002).

The predictions concerning the effects of the D1866Y mutation on neuronal firing were tested using the NEURON simulation software (Figs. 5, 6). Modeling of the D1866Y mutation suggests that a positive shift in the voltage dependence of sodium channel inactivation results in reduced latency between the input stimulus and generation of an action potential. The mutant model neuron fired action potentials with shorter spike-to-spike intervals that occurred earlier during the stimulus. A similar effect has been reported in partially kindled rats (Zhao and Leung, 


\section{Effects of Subthreshold Stimuli}
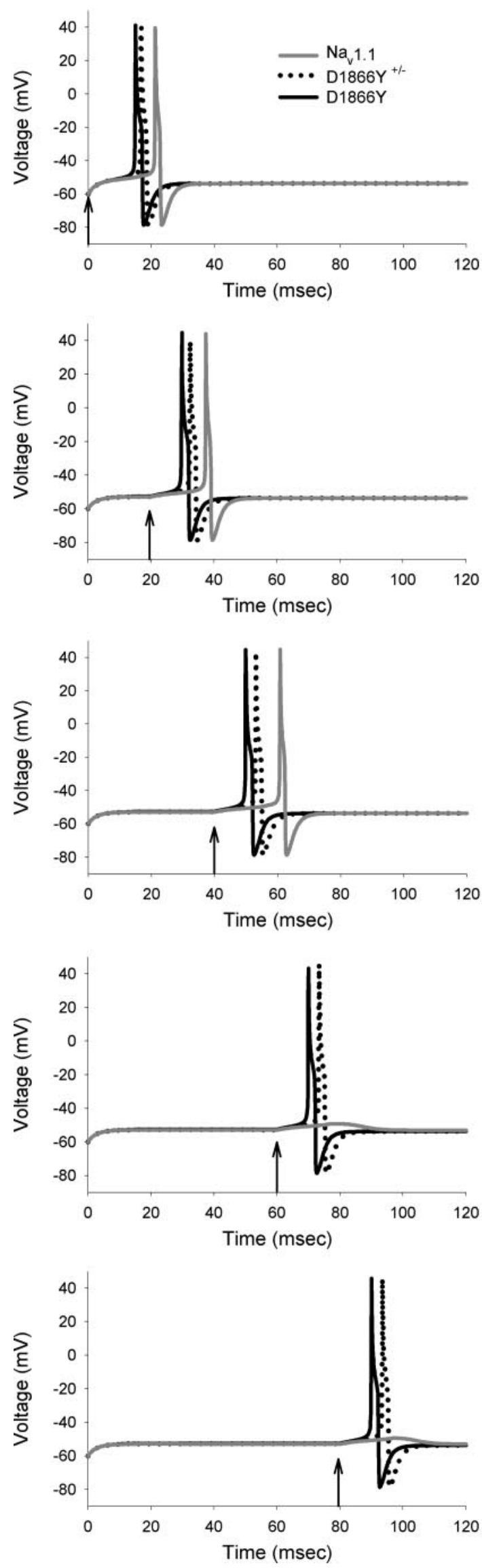

Table 4. Interaction between C-terminal fragments of $\alpha$ and $\beta$ subunits in the yeast two-hybrid assay

\begin{tabular}{llll}
\hline$\alpha$ Construct & $\beta_{1}$ & $\beta_{2}$ & $\beta_{3}$ \\
\hline Wild-type $\alpha$ 226 & $3 / 3$ & $0 / 4$ & $3 / 3$ \\
Wild-type $\alpha 41$ & $2 / 2$ & $0 / 2$ & $2 / 2$ \\
D1866Y $\alpha$ 226 & $3 / 3$ & $0 / 4$ & $3 / 3$ \\
D1866Y $\alpha 41$ & $2 / 2$ & $0 / 2$ & $2 / 2$ \\
\hline
\end{tabular}

Sodium channel fragments encoding the complete 226 amino acid C terminus of the $\alpha$ subunit $(\alpha-226)$ or the 41 amino acid polypeptide from the middle of the $C$ terminus centered on residue $1866(\alpha-41)$ were cloned into vector A. Fragments containing the 36 amino acid $C$ terminus of the $\beta 1$ subunit, the 32 amino acid $C$ terminus of the $\beta 2$ subunit, or the 34 amino acid C terminus of the $\beta 3$ subunit were cloned into expression vector $B$. The interaction between the coexpressed $\mathrm{Na}_{v} 1.1$ and $\beta$ fragments was recognized by staining colonies for $\beta$-galactosidase activity. The data represent the number of experiments demonstrating interaction divided by the total number of experiments for each pair of constructs.

1993), suggesting a possible link between changes in sodium channel inactivation, generation of early onset action potentials, and the development of spontaneous seizures. It is important to note that our model is simplified and that kindling is a complex cellular and molecular process involving any number of physiological and genetic changes leading to spontaneous seizures (Mody, 1993; McNamara, 1994). It is possible that neurons expressing the D1866Y mutant sodium channels may be capable of recruiting synaptically distant neurons and networks of neurons to begin to fire on an accelerated timing pattern during interictal periods, which could perpetuate until an unmanageable hypersynchronous discharge is produced.

The most significant functional effects of the D1866Y mutation were observed in the presence of the $\beta 1$ subunit, suggesting that this mutation might be located in a cytoplasmic domain that mediates direct interaction between $\alpha$ and $\beta$ subunits. Extracellular interaction between $\alpha$ and $\beta 1$ subunits is known to be mediated by residues in the pore region of the $\alpha$ subunit and the A/A' face of the Ig domain of $\beta 1$ (McCormick et al., 1998, 1999; Qu et al., 1999). A GEFS + 1 mutation in the extracellular domain of $\beta 1, \mathrm{C} 121 \mathrm{~W}$, does not prevent interaction with sodium channel $\alpha$ subunits or promotion of channel cell surface expression but does prevent complete $\beta 1$-mediated modulation of sodium channel function (Meadows et al., 2002).

Several previous studies indicated that the intracellular segment of $\beta 1$ is also involved in modulation of the $\alpha$ subunit. $\beta 1_{\text {STOP }}$, a $\beta 1$ truncation mutant that lacks the intracellular domain, modulates $\mathrm{Na}_{\mathrm{v}} 1.2$ function similarly to wild-type $\beta 1$ when coinjected into Xenopus oocytes at a high $\beta 1_{\mathrm{STOP}} / \alpha$ concentration ratio (Chen and Cannon, 1995; Meadows et al., 2001). However, when coexpressed in mammalian cells, $\beta 1_{\text {STOP }}$ interacts weakly with $\mathrm{Na}_{\mathrm{v}} 1.2$ and does not modulate channel function (Meadows et al., 2001). The $\beta 1$ cytoplasmic mutant Y181E interacts efficiently with $\mathrm{Na}_{\mathrm{v}} 1.2$ in mammalian cells but does not

$\leftarrow$

Figure 6. The D1866Y mutant model neuron is resilient to subthreshold stimuli. Increasing duration subthreshold current injections of $60 \mathrm{pA}$ were applied to wild-type $\mathrm{Na}_{v} 1.1$ (gray traces), mutant D1866Y (black traces), and a 1:1 heterozygous population of mutant and wildtype (D1866 $\mathrm{Y}^{+/-}$; dotted traces) model neurons. The conditioning depolarizations were immediately followed by injection of an additional $10 \mathrm{pA}$ of current to test for action potential generation. Each plot begins with the application of the $60 \mathrm{pA}$ conditioning pulse, and the arrows indicate the time point at which the additional $10 \mathrm{pA}$ test injection was applied. The top panel shows a 0 -msec-long conditioning pulse as a positive control. The D1866Y and D1866 $\mathrm{Y}^{+/-}$model neurons fired single action potentials with shorter onset delays than for $\mathrm{Na}_{\mathrm{v}} 1.1$ after subthreshold stimuli up to $40 \mathrm{msec}$. In addition, the D1866Y and D1866Y $\mathrm{Y}^{+1-}$ model neurons remained capable of firing action potentials after longer subthreshold stimuli, whereas the $\mathrm{Na}_{\mathrm{v}} 1.1$ model neurons did not fire action potentials after subthreshold stimuli of 60 msec or longer. 


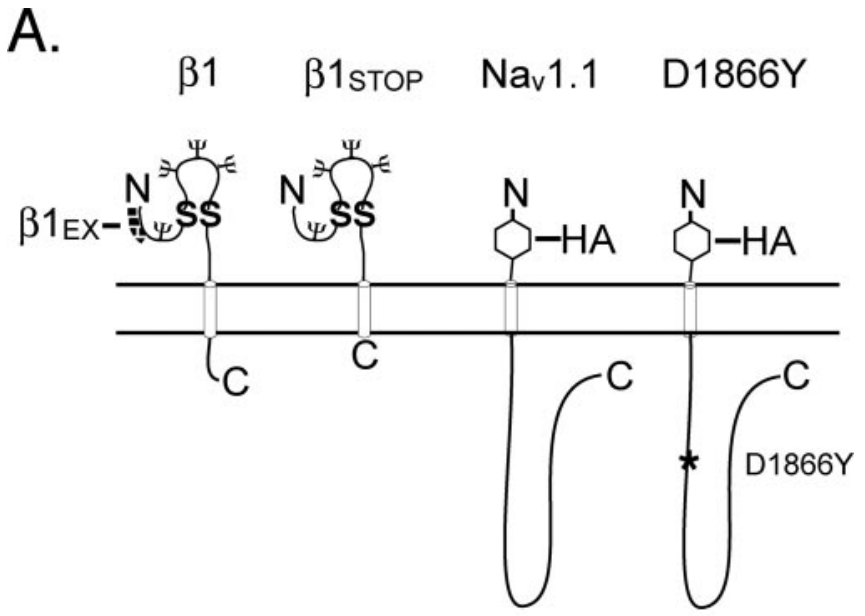

B.

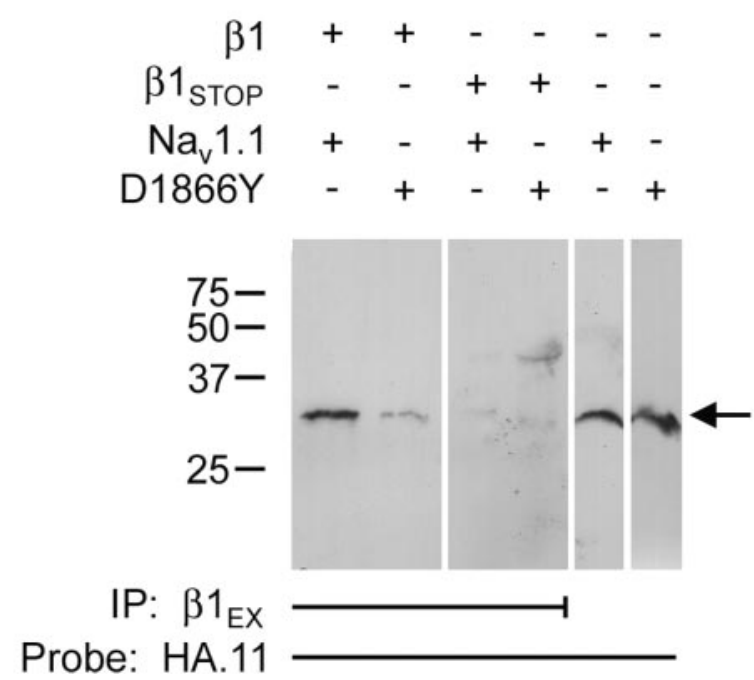

Figure 7. The cytoplasmic C-terminal domain of $\mathrm{Na}_{\mathrm{v}} 1.1$ interacts directly with $\beta 1$, and the D1866Y mutation impairs that interaction. $A$, Structure of mammalian expression constructs containing the transmembrane segment and C-terminal domains of $\mathrm{Na}_{\mathrm{v}} 1.1$ or full-length $\beta 1$. $B$, Lysates from Chinese hamster lung fibroblasts transfected with the constructs shown in $A$ were immunoprecipitated with $5 \mu$ lof $\beta 1_{\mathrm{Ex}}$ antibody specific for the extracellular domain of the $\beta 1$ subunit. Immunoblots were probed with anti-HA.11 antibody (1:1000) directed toward the epitope tag on the $\mathrm{Na}_{v} 1.1$ constructs. The untreated lysates in lanes 5 and 6 demonstrate equivalent expression of the wild-type and mutant $\mathrm{Na}_{\mathrm{v}} 1.1$ constructs in the transfected cells.

modulate sodium channel function and does not promote sodium channel cell surface expression (McEwen et al., 2004). Taken together, these studies support the hypothesis that $\beta 1$ subunits contain multiple extracellular and intracellular $\alpha$ interaction domains and that all of these domains must be intact for complete $\beta 1$-mediated modulation of $\alpha$ to occur. The previous studies did not define the residues of the $\alpha$ subunit $\mathrm{C}$ terminus that interact with $\beta 1$. Identification of the GEFS + mutation D1866Y enabled us to begin to define this interaction site.

Expression of the $\alpha$ and $\beta$ cytoplasmic domains as "bait" and "prey" in the yeast two-hybrid system demonstrated interaction of the $\mathrm{Na}_{\mathrm{v}} 1.1 \alpha$ subunit with the $\mathrm{C}$ termini of the $\beta 1$ and $\beta 3$ subunits, whereas the more distantly related $\beta 2$ subunit did not interact. The 41 residue $\alpha$ subunit fragment K1846-R1886, containing residue D1866, was as effective as the full-length C terminus. The interaction was confirmed by coimmunoprecipitation after transfection of mammalian cells with constructs containing the cytoplasmic domain of $\alpha$ and full-length $\beta 1$ subunits. The interaction of the $\mathrm{Na}_{\mathrm{v}} 1.1 \mathrm{C}$-terminal domain with intact $\beta 1$ in transfected cells was significantly reduced by the D1866Y mutation, providing evidence for the mechanism of this disease mutation. The experiments indicate that D1866Y destabilizes the $\alpha / \beta 1$ subunit complex, thereby abolishing some, but not all, of the $\beta 1$-mediated biophysical effects on $\mathrm{Na}_{\mathrm{v}} 1.1$, in heterozygous carriers of the mutation. We were unable to test the interaction of full-length $\mathrm{Na}_{\mathrm{v}} 1.1-\mathrm{D} 1866 \mathrm{Y}$ with $\beta 1$, and thus we do not know whether the native proteins would associate despite the presence of the mutation, as shown for $\beta 1 \mathrm{C} 121 \mathrm{~W}$ and $\beta 1 \mathrm{Y} 181 \mathrm{E}$ (Meadows et al., 2002; McEwen et al., 2004). Nevertheless, the position of the mutation defines a new $\alpha / \beta 1$ interaction domain at the distal end of the highly conserved proximal half of the C-terminal cytoplasmic domain of $\alpha$ and strengthens our hypothesis that $\beta 1$ may play critical roles in the regulation of neuronal hyperexctiability by modulating $\alpha$ subunit function (Fig. $1 C$ ). Interestingly, no changes in sodium current properties were observed in hippocampal neurons isolated from $\beta 1(-/-)$ mice despite a hyperexcitable phenotype that includes severe spontaneous seizures (C. Chen et al., 2004). It is possible that $\beta 3$ subunits may substitute for $\beta 1$ in these mice in terms of the electrophysiological modulation of sodium channel function. The results of the present study support this hypothesis, in that $\beta 3$ also associates with the $\mathrm{Na}_{\mathrm{v}} 1.1 \mathrm{C}$ terminus as assessed by yeast two-hybrid analysis.

The LQT3 mutation D1790G in the C terminus of the $\alpha$ subunit gene SCN5A also reduces interaction with the $\beta 1$ subunit (An et al., 1998). This mutation corresponds to residue D1803 in SCN1A, which is outside of the active 41 residue fragment of SCN1A. The active SCN1A fragment K1846-R1886 contains the predicted $\alpha$ helices 5 and 6 identified in SCN5A (Cormier et al., 2002) and also contains a di-leucine signal that is required for axonal localization of SCN2A $\left(\mathrm{Na}_{\mathrm{v}} 1.2\right)$ (Garrido et al., 2001). Another GEFS + mutation was recently identified within the K1846-R1886 peptide (Annesi et al., 2003). It will be of great interest to determine whether this mutation also reduces $\beta 1$ subunit interaction.

The D1866Y mutation in $\mathrm{Na}_{\mathrm{v}} 1.1$ results in a positive shift in the voltage dependence of sodium channel inactivation, and this is predicted by the NEURON model to lead to neuronal hyperexcitability. Our findings, together with previous results from other groups, suggest that the voltage dependence of sodium channel inactivation is a key feature determining whether a neuron will behave in a hyperexcitable manner like the D1866Y mutant, resulting in seizure activity, or in a hypoexcitable manner to eliminate seizure activity, as seen in the presence of the anticonvulsants valproate, lamotrigine, and carbamazepine.

\section{References}

Abou-Khalil B, Ge Q, Desai R, Ryther R, Bazyk A, Bailey R, Haines JL, Sutcliffe JS, George JR AL (2001) Partial and generalized epilepsy with febrile seizures plus and a novel SCN1A mutation. Neurology 57:2265-2272.

Abriel H, Cabo C, Wehrens XHT, Rivolta I, Motoike HK, Memmi M, Napolitano C, Priori SG, Kass RS (2001) Novel arrhythmogenic mechanism revealed by a long-QT syndrome mutation in the cardiac $\mathrm{Na}^{+}$channel. Circ Res 88:740-745.

An R-H, Wang XL, Kerem B, Benhorin J, Medina A, Goldmit M, Kass RS (1998) Novel LQT-3 mutation affects $\mathrm{Na}^{+}$channel activity through interactions between $\alpha$ - and $\beta_{1}$-subunits. Circ Res 83:141-146.

Annesi G, Gambardella A, Carrideo S, Incorpora G, Labate A, Pasqua AA, Civitelli D, Polizzi A, Annesi F, Spadafora P, Tarantino P, Cirò Candiano IC, Romeo N, De Marco EV, Ventura P, LePiane E, Zappia M, Aguglia U, Pavone L, Quattrone A (2003) Two novel SCN1A missense mutations in generalized epilepsy with febrile seizures plus. Epilepsia 44:1257-1258. 
Ausubel FM, Brent R, Kingston RE, Moore DD, Seidman JG, Smith JA, Struhl K (1987) Current protocols in molecular biology. New York: Greene and Wiley.

Black JA, Yokoyama S, Higashida H, Ransom BR, Waxman SG (1994) Sodium channel mRNAs I, II and III in the CNS: cell-specific expression. Mol Brain Res 22:275-289.

Breeden L, Nasmyth K (1985) Regulation of the yeast HO gene. Cold Spring Harbor Symp Quant Biol 50:643-650.

Catterall WA (2000) From ionic currents to molecular mechanisms: the structure and function of voltage-gated sodium channels. Neuron 26:13-25.

Chen C, Cannon SC (1995) Modulation of $\mathrm{Na}^{+}$channel inactivation by the $\beta_{1}$ subunit: a deletion analysis. Pflügers Arch 431:186-195.

Chen C, Westenbroek RE, Xu X, Edwards CA, Sorenson DR, Chen Y, McEwen DP, O'Malley HA, Bharucha V, Meadows LS, Knudsen GA, Vilaythong A, Noebels JL, Saunders TL, Scheuer T, Shrager P, Catterall WA, Isom LL (2004) Mice lacking sodium channel $\beta 1$ subunits display defects in neuronal excitability, sodium channel expression, and nodal architecture. J Neurosci 24:4030-4042.

Chen Q, Kirsch GE, Zhang D, Brugada R, Brugada J, Brugada P, Potenza D, Moya A, Borggrefe M, Breithardt G, Ortiz-Lopez R, Wang Z, Antzelevitch C, O’Brien RE, Schulze-Bahr E, Keating MT, Towbin JA, Wang Q (1998) Genetic basis and molecular mechanism for idiopathic ventricular fibrillation. Nature 392:293-296.

Cormier JW, Rivolta I, Tateyama M, Yang A-S, Kass RS (2002) Secondary structure of the human cardiac $\mathrm{Na}^{+}$channel $\mathrm{C}$ terminus. Evidence for a role of helical structures in modulation of channel inactivation. J Biol Chem 277:9233-9241.

Cossette P, Loukas A, Lafrenière RG, Rochefort D, Harvey-Girard E, Ragsdale DS, Dunn RJ, Rouleau GA (2003) Functional characterization of the D188V mutation in neuronal voltage-gated sodium channel causing generalized epilepsy with febrile seizures plus (GEFS). Epilepsy Res 53:107-117.

Cummins TR, Zhou J, Sigworth FJ, Ukomadu C, Stephan M, Ptácek LJ, Agnew WS (1993) Functional consequences of a sodium channel mutation causing hyperkalemic periodic paralysis. Neuron 10:667-678.

Deschênes I, Trottier E, Chahine M (2001) Implication of the C-terminal region of the $\alpha$-subunit of voltage-gated sodium channels in fast inactivation. J Membr Biol 183:103-114.

Dichter MA (1991) The epilepsies and convulsive disorders. In: Harrison's principles of internal medicine (Wilson JD, Braunwald E, Isselbacher KJ, Petersdorf RG, Martin JB, Fauci AS, Root RK, eds), pp 1968-1977. New York: McGraw-Hill.

Dichter MA (1994) Emerging insights into mechanisms of epilepsy: implications for new antiepileptic drug development. Epilepsia 35:S51-S57.

Doose H (1989) Symptomatology in children with focal sharp waves of genetic origin. Eur J Pediatr 149:210-215.

Doose H (1992) Myoclonic-astatic epilepsy. Epilepsy Res Suppl 6:163-168.

Dubreuil RR, MacVicar G, Dissanayake S, Liu C, Homer D, Hortsch M (1996) Neuroglian-mediated cell adhesion induces assembly of the membrane skeleton at cell contact sites. J Cell Biochem 133:647-655.

Ellerkmann RK, Remy S, Chen J, Sochivko D, Elger CE, Urgan BW, Becker A, Beck H (2003) Molecular and functional changes in voltage-dependent $\mathrm{Na}^{+}$channels following pilocarpine-induced status epilepticus in rat dentate granule cells. Neuroscience 119:323-333.

Escayg A, MacDonald BT, Meisler MH, Baulac S, Huberfeld G, AnGourfinkel I, Brice A, LeGuern E, Moulard B, Chaigne D, Buresi C, Malafosse A (2000) Mutations of SCN1A, encoding a neuronal sodium channel, in two families with GEFS+2. Nat Genet 24:343-345.

Escayg A, Heils A, MacDonald BT, Haug K, Sander T, Meisler MH (2001) A novel SCN1A mutation associated with generalized epilepsy with febrile seizures plus and prevalence of variants in patients with epilepsy. Am J Hum Genet 68:866-873.

Fujiwara T, Sugawara T, Mazaki-Miyazaki E, Takahashi Y, Fukushima K, Watanabe M, Hara K, Morikawa T, Yagi K, Yamakawa K, Inoue Y (2003) Mutations of sodium channel $\alpha$ subunit type 1 (SCN1A) in intractable childhood epilepsies with frequent generalized tonix-clonic seizures. Brain 126:531-546.

Furuyama T, Morita Y, Inagaki S, Takagi H (1993) Distribution of I, II and III subtypes of voltage-sensitive $\mathrm{Na}^{+}$channel mRNA in the rat brain. Mol Brain Res 17:169-173.

Garrido JJ, Fernandes F, Giraud P, Mouret I, Pasqualini E, Fache M-P, Jullien
F, Dargent B (2001) Identification of an axonal determinant in the C-terminus of the sodium channel $\mathrm{Na}_{\mathrm{v} 1.2}$. EMBO J 20:5950-5961.

Goldin AL (1991) Expression of ion channels by injection of mRNA into Xenopus oocytes. Methods Cell Biol 36:487-509.

Goldin AL (2001) Resurgence of sodium channel research. Annu Rev Physiol 63:871-894.

Goldin AL, Barchi RL, Caldwell JH, Hofmann F, Howe JR, Hunter JC, Kallen RG, Mandel G, Meisler MH, Berwald-Netter Y, Noda M, Tamkun MM, Waxman SG, Wood JN, Catterall WA (2000) Nomenclature of voltagegated sodium channels. Neuron 28:365-368.

Green DS, George Jr AL, Cannon SC (1998) Human sodium channel gating defects caused by missense mutations in S6 segments associated with myotonia: S804F and V1293I. J Physiol (Lond) 510:685-694.

Gu XQ, Yao H, Haddad GG (2001) Increased neuronal excitability and seizures in the $\mathrm{Na}^{+} / \mathrm{H}^{+}$exchanger null mutant mouse. Am J Physiol Cell Physiol 281:C496-C503.

Hayward LJ, Brown Jr RH, Cannon SC (1996) Inactivation defects caused by myotonia-associated mutations in the sodium channel III-IV linker. J Gen Physiol 107:559-576.

Hines ML, Carnevale NT (1997) The NEURON simulation environment. Neural Comput 9:1179-1209.

Isom LL, DeJongh KS, Catterall WA (1994) Auxiliary subunits of voltagegated ion channels. Neuron 12:1183-1194.

Kearney JA, Plummer NW, Smith MR, Kapur J, Cummins TR, Waxman SG, Goldin AL, Meisler MH (2001) A gain-of-function mutation in the sodium channel gene $S c n 2 a$ results in seizures and behavioral abnormalities. Neuroscience 102:307-317.

Ketelaars SOM, Gorter JA, van Vliet EA, Lopes da Silva FH, Wadman WJ (2001) Sodium currents in isolated rat CA1 pyramidal and dentate granule neurones in the post-status epilepticus model of epilepsy. Neuroscience 105:109-120.

Köhling R (2002) Voltage-gated sodium channels in epilepsy. Epilepsia 43: $1278-1295$.

Kontis KJ, Rounaghi A, Goldin AL (1997) Sodium channel activation gating is affected by substitutions of voltage sensor positive charges in all four domains. J Gen Physiol 110:391-401.

Kuo C-C (1998) A common anticonvulsant binding site for phenytoin, carbamazepine, and lamotrigine in neuronal $\mathrm{Na}^{+}$channels. Mol Pharmacol 54:712-721.

Kuo C-C, Lu L (1997) Characterization of lamotrigine inhibition of $\mathrm{Na}^{+}$ channels in rat hippocampal neurones. Br J Pharmacol 121:1231-1238.

Kuo C-C, Chen R-S, Lu L, Chen R-C (1997) Carbamazepine inhibition of neuronal $\mathrm{Na}^{+}$currents: quantitative distinction from phenytoin and possible therapeutic implications. Mol Pharmacol 51:1077-1083.

Lossin C, Wang DW, Rhodes TH, Vanoye CG, George Jr AL (2002) Molecular basis of an inherited epilepsy. Neuron 34:877-884.

Lossin C, Rhodes TH, Desai RR, Vanoye CG, Wang D, Carniciu S, Devinsky O, George Jr AL (2003) Epilepsy-associated dysfunction in the voltagegated neuronal sodium channel SCN1A. J Neurosci 23:11289-11295.

Malhotra JD, Kazen-Gillespie K, Hortsch M, Isom LL (2000) Sodium channel $\beta$ subunits mediate homophilic cell adhesion and recruit ankyrin to points of cell-cell contact. J Biol Chem 275:11383-11388.

Mantegazza M, Yu FH, Catterall WA, Scheuer T (2001) Role of the C-terminal domain in inactivation of brain and cardiac sodium channels. Proc Natl Acad Sci USA 98:15348-15353.

McCormick KA, Isom LL, Ragsdale D, Smith D, Scheuer T, Catterall WA (1998) Molecular determinants of $\mathrm{Na}^{+}$channel function in the extracellular domain of the $\beta 1$ subunit. J Biol Chem 273:3954-3962.

McCormick KA, Srinivasan J, White K, Scheuer T, Catterall WA (1999) The extracellular domain of the $\beta 1$ subunit is both necessary and sufficient for $\beta 1$-like modulation of sodium channel gating. J Biol Chem 274:32638-32646.

McEwen DP, Meadows LS, Chen C, Thyagarajan V, Isom LL (2004) Sodium channel $\beta 1$ subunit-mediated modulation of $\mathrm{Na}_{\mathrm{v}} 1.2$ currents and cell surface density is dependent on interactions with contactin and ankyrin. J Biol Chem 279:16044-16049.

McNamara JO (1994) Cellular and molecular basis of epilepsy. J Neurosci 14:3413-3425.

Meadows L, Malhotra JD, Stetzer A, Isom LL, Ragsdale DS (2001) The intracellular segment of the sodium channel $\beta 1$ subunit is required for its efficient association with the channel $\alpha$ subunit. J Neurochem 76:1871-1878. 
Meadows LS, Malhotra A, Loukas A, Thyagarajan V, Kazen-Gillespie KA, Koopmann MC, Kriegler S, Isom LL, Ragsdale DS (2002) Functional and biochemical analysis of a sodium channel $\beta 1$ subunit mutation responsible for generalized epilepsy with febrile seizures plus type 1. J Neurosci 22:10699-10709.

Meisler MH, Kearney J, Ottman R, Escayg A (2001) Identification of epilepsy genes in human and mouse. Annu Rev Genet 35:567-588.

Mitrovic N, George AL Jr, Lerche H, Wagner S, Fahlke C, Lehmann-Horn F (1995) Different effects on gating of three myotonia-causing mutations in the inactivation gate of the human muscle sodium channel. J Physiol (Lond) 487:107-114.

Mody I (1993) The molecular basis of kindling. Brain Pathol 3:395-403.

Novakovic SD, Eglen RM, Hunter JC (2001) Regulation of $\mathrm{Na}^{+}$channel distribution in the nervous system. Trends Neurosci 24:473-478.

Plummer NW, Meisler MH (1999) Evolution and diversity of mammalian sodium channel genes. Genomics 57:323-331.

Pritchard JK (2001) Are rare variants responsible for susceptibility to complex diseases? Am J Hum Genet 69:124-137.

Pugsley MK, Yu EJ, McLean TH, Goldin AL (1999) Blockade of neuronal sodium channels by the antiepileptic drugs phenytoin, carbamazepine and sodium valproate. Proc West Pharmacol Soc 42:105-108.

Qu Y, Rogers JC, Chen S-F, McCormick KA, Scheuer T, Catterall WA (1999) Functional roles of the extracellular segments of the sodium channel $\alpha$ subunit in voltage-dependent gating and modulation by $\beta 1$ subunits. J Biol Chem 274:32647-32654.

Reckziegel G, Beck H, Schramm J, Urgan BW, Elger CE (1999) Carbamazepine effects on $\mathrm{Na}^{+}$currents in human dentate granule cells from epileptogenic tissue. Epilepsia 40:401-407.

Rook MB, Alshinawi CB, Groenewegen WA, van Gelder IC, van Ginneken ACG, Jongsma HJ, Mannens MMAM, Wilde AAM (1999) Human SCN5A gene mutations alter cardiac sodium channel kinetics and are associated with the Brugada syndrome. Circ Res 44:507-517.

Scheffer IE, Berkovic SF (1997) Generalized epilepsy with febrile seizures plus. A genetic disorder with heterogeneous clinical phenotypes. Brain 120:479-490.

Siep E, Richter A, Löscher W, Speckmann E-J, Köhling R (2002) Sodium currents in striatal neurons from dystonic $\mathrm{dt}^{\mathrm{SZ}}$ hamsters: altered response to lamotrigine. Neurobiol Dis 9:258-268.

Singh R, Scheffer IE, Crossland K, Berkovic SF (1999) Generalized epilepsy with febrile seizures plus: a common childhood-onset genetic epilepsy syndrome. Ann Neurol 45:75-81.

Smith MR, Goldin AL (1999) A mutation that causes ataxia shifts the voltage-dependence of the Scn8a sodium channel. NeuroReport 10:3027-3031.

Smith RD, Goldin AL (1998) Functional analysis of the rat I sodium channel in Xenopus oocytes. J Neurosci 18:811-820.

Spampanato J, Escayg A, Meisler MH, Goldin AL (2001) Functional effects of two voltage-gated sodium channel mutations that cause generalized epilepsy with febrile seizures plus type 2. J Neurosci 21:7481-7490.
Spampanato J, Escayg A, Meisler MH, Goldin AL (2003) The generalized epilepsy with febrile seizures plus type 2 mutation W1204R alters voltagedependent gating of $\mathrm{Na}_{\mathrm{v}} 1.1$ sodium channels. Neuroscience 116:37-48.

Spampanato J, Aradi I, Soltesz I, Goldin AL (2004) Increased neuronal firing in computer simulations of sodium channel mutations that cause generalized epilepsy with febrile seizures plus. J Neurophysiol 91:2040-2050.

Sugawara T, Mazaki-Miyazaki E, Ito M, Nagafuji H, Fukuma G, Mitsudome A, Wada K, Kaneko S, Hirose S, Yamakawa K (2001) Nav1.1 mutations cause febrile seizures associated with afebrile partial seizures. Neurology 57:703-705.

Vreugdenhil M, Wadman WJ (1999) Modulation of sodium currents in rat CA1 neurons by carbamazepine and valproate after kindling epileptogenesis. Epilepsia 40:1512-1522.

Vreugdenhil M, Faas GC, Wadman WJ (1998) Sodium currents in isolated rat CA1 neurons after kindling epileptogenesis. Neuroscience 86:99-107.

Wallace RH, Scheffer IE, Barnett S, Richards M, Dibbens L, Desai RR, Lerman-Sadie T, Lev D, Mazarib A, Brand N, Ben-Zeev B, Goikhman I, Singh R, Kremmidiotis G, Gardner A, Sutherland GR, George Jr AL, Mulley JC, Berkovic SF (2001) Neuronal sodium-channel $\alpha 1$-subunit mutations in generalized epilepsy with febrile seizures plus. Am J Hum Genet 68:859-865.

Wallace RH, Hodgson BL, Grinton BE, Gardiner RM, Robinson R, Rodriguez-Casero V, Sadleir L, Morgan J, Harkin LA, Dibbens LM, Yamamoto T, Andermann E, Mulley JC, Berkovic SF, Scheffer IE (2003) Sodium channel $\alpha 1$-subunit mutations in severe myoclonic epilepsy of infancy and infantile spasms. Neurology 61:765-769.

Wehrens XHT, Abriel H, Cabo C, Benhorin J, Kass RS (2000) Arrhythmogenic mechanism of an LQT-3 mutation of the human heart $\mathrm{Na}^{+}$channel $\alpha$-subunit. A computational analysis. Circulation 102:584-590.

Westenbroek RE, Merrick DK, Catterall WA (1989) Differential subcellular localization of the $\mathrm{R}_{\mathrm{I}}$ and $\mathrm{R}_{\mathrm{II}} \mathrm{Na}^{+}$channel subtypes in central neurons. Neuron 3:695-704.

Whitaker WRJ, Clare JJ, Powell AJ, Chen YH, Faull RLM, Emson PC (2000) Distribution of voltage-gated sodium channel $\alpha$-subunit and $\beta$-subunit mRNAs in human hippocampal formation, cortex, and cerebellum. J Comp Neurol 422:123-139.

Xie X, Lancaster B, Peakman T, Garthwaite J (1995) Interaction of the antiepileptic drug lamotrigine with recombinant rat brain type IIA $\mathrm{Na}^{+}$channels and with native $\mathrm{Na}^{+}$channels in rat hippocampal neurones. Pflügers Arch 430:437-446.

Yu FH, Westenbroek RE, Silos-Santiago I, McCormick KA, Lawson D, Ge P, Ferriera H, Lilly J, Distefano PS, Catterall WA, Scheuer T, Curtis R (2003) Sodium channel $\beta 4$, a new disulfide-linked auxiliary subunit with similarity to $\beta 2$. J Neurosci 23:7577-7585.

Zhao D, Leung LS (1993) Partial hippocampal kindling increases pairedpulse facilitation and burst frequency in hippocampal CA1 neurons. Neurosci Lett 154:191-194.

Zona C, Avoli M (1997) Lamotrigine reduces voltage-gated sodium currents in rat central neurons in culture. Epilepsia 38:522-525. 